\title{
HEAT TRANSFER ANALYSIS IN A TURBOCHARGER TURBINE: AN EXPERIMENTAL AND COMPUTATIONAL EVALUATION
}

\author{
A. Romagnoli and R. Martinez-Botas ${ }^{1}$ \\ Department of Mechanical Engineering \\ Imperial College London \\ SW7 2AZ Exhibition Road \\ London, UK
}

\begin{abstract}
This paper presents the performance of a turbocharger under non-adiabatic conditions in order to assess the impact of heat transfer. A commercial turbocharger was installed on a 2.0 liter diesel engine and measurements were conducted for a range of engine speeds and loads. The test results enabled to assess the impact of the engine on the temperature distribution of the bodies constituting the turbocharger, quantify the heat fluxes through the turbocharger and evaluate their effects on the deterioration of compressor performance.

A 1-D heat transfer model was also developed and validated against the experimental measurements. The algorithms calculate the heat transferred through the turbocharger by means of lump capacitances. Compressor maps were then generated for a range of speeds and temperatures of the exhaust gases at the inlet to turbine and the efficiency drop associated with heat transfer was quantified. Based on the data generated by the model, a new correlation for the compressor non-adiabatic efficiency was found by means of a multiple regression analysis; the work is based on a statistical description of the different parameters that affect the heat transfer model.
\end{abstract}

Keywords: heat transfer, turbocharger, performance, non adiabatic

\section{NOMENCLATURE}

$\begin{array}{lll}\text { C } & \text { Absolute velocity } & {[\mathrm{m} / \mathrm{s}]} \\ \text { D } & \text { External Diameter } & {[\mathrm{m}]} \\ \mathrm{c}_{\mathrm{p}} & \text { Specific heat of air } & {[\mathrm{J} / \mathrm{Kg} \cdot \mathrm{K}]} \\ \mathrm{h} & \text { Heat coefficient } & \end{array}$

\footnotetext{
${ }^{1}$ Corresponding author:

Ricardo Martinez-Botas, r.botas@imperial.ac.uk | Tel. +44 (0) 2075947241 | Fax: +44 (0) 2078238845
} 
L Length

k Thermal conductivity

M Mach number

$\mathrm{M}_{\mathrm{u}} \quad$ Peripheral Mach number

MFP Mass flow parameter

$\dot{m} \quad$ Mass flow rate

$\mathrm{N} \quad$ Pseudo-dimensional speed

$\mathrm{Nu} \quad$ Nusselt number

PR Pressure ratio

rpm Revolution per minute

q Specific amount of heat transfer

$\dot{Q} \quad$ Heat flux

R Universal gas constant

$\mathrm{Ra} \quad$ Rayleigh number

T Temperature

U Blade speed

$\mathrm{x} \quad$ Axial direction, Explanatory variable $[m]$

$[W / m K]$

$[(K g / s) \cdot \sqrt{ } K / P a]$

$[\mathrm{Kg} / \mathrm{s}]$

$[\mathrm{rev} / \mathrm{s} \cdot \sqrt{ } K]$

$[\mathrm{rev} / \mathrm{min}]$

$[\mathrm{J} / \mathrm{Kg}]$

$[J / s]$

$[\mathrm{J} / \mathrm{Kmol}]$

[K]

$[\mathrm{m} / \mathrm{s}]$

\section{GREEKS}

$\gamma \quad$ Ratio of specific heat

$\eta \quad$ Efficiency

$\sigma \quad$ Boltzmann constant

$[J / K]$

$\mu \quad$ Slip factor

$\rho \quad$ Density

$\left[\mathrm{Kg} / \mathrm{m}^{3}\right]$

$\phi \quad$ Flow coefficient

$\theta \quad$ Tangential component

\section{NUMBERS}

$0 \quad$ Total conditions

1 Inlet to the compressor

1* Inlet to the impeller

2 Exit to the compressor

$2^{*} \quad$ Exit to the compressor impeller 
$4 \quad$ Exit to the turbine

\section{SUBSCRIPTS}

\begin{tabular}{|c|c|}
\hline adi & Adiabatic \\
\hline after & State after compression or expansion \\
\hline B & Blade \\
\hline $\mathrm{BH}$ & Bearing Housing \\
\hline $\mathrm{BP}$ & Back-plate \\
\hline before & State before compression or expansion \\
\hline bs & Back-swept \\
\hline $\mathrm{c}$ & Compressor \\
\hline conv & Convection \\
\hline cond & Conduction \\
\hline dia & Non-adiabatic \\
\hline Exh & Exhaust \\
\hline fc & Forced convection \\
\hline is & isentropic \\
\hline $\mathrm{m}$ & Meridional \\
\hline $\mathrm{r}$ & Radial \\
\hline $\mathrm{rad}$ & Radiation \\
\hline S & Shaft \\
\hline surf & Surface \\
\hline $\mathrm{t}$ & Turbine \\
\hline $\mathrm{W}$ & Wall \\
\hline Wc & Wall compressor \\
\hline $\mathrm{Wt}$ & Wall turbine \\
\hline
\end{tabular}

\section{INTRODUCTION}

In the past years there has been increased interest and attention on turbochargers technology driven by engine demand. Turbochargers are widely used in diesel engines; they represent a key enabling technology to achieve highly downsized engines for both compression ignition and spark ignition technology. Extensive research on turbochargers resulted in a significant understanding of their aerodynamic behavior. In this manner optimization of design procedures have been demonstrated closely coupled with the 
development of simulation tools. Similar efforts have not been employed on the heat transfer area in turbochargers. Clearly as engine developers try to meet stringent demands, any affordable raise in engine efficiency is highly regarded. The approach of this paper tries to contribute, yet in a simplified manner, to raise the level of the heat transfer analysis. Amongst the main causes that have discouraged efforts on this topic, lack of understanding of the heat effects as well as the high costs associated with testing facilities. Although researchers have shown that heat transfer is not small, the compression and expansion process within turbochargers are still considered to be adiabatic.

Rautenberg et al. [1] and Rautenberg and Krammer [2] investigated the influence of heat transfer from the turbine (hot side) to the compressor (cold side). They found that the heat transferred to the compressor increases the compressor outlet temperature increases the compressor outlet temperature, compared if the compressor was adiabatic. Shaaban and Seume [3] identified the main parameters affecting the deterioration of the compressor efficiency in hot conditions through a theoretical and experimental investigation. The compressor peripheral Mach number was found to be one of the most important parameters affecting the turbocharger non-adiabatic performance. Shaaban [4] also proposed an analytical solution for determining the temperature distribution along the bearing housing taking into account the heat dissipated by free convection to the surroundings, the heat conduction to the bearing housing and the forced convection to the oil. The results of this approach enabled them to determine the exit temperature in the turbine to within $\pm 1.98 \%$. Hagelstein et al. [5] assumed that the heat transferred during the compression and expansion process can be neglected without affecting the global result. Similarly to Jung et al. [6], Cormerais et al. [7] proposed a heat transfer model to determine the temperature difference between the exhaust and intake manifold. This model did not need to be fitted with constants but only took into account the convective heat transfer within the bearing housing.

Seume [3] and Abdelhamid et al. [8] measured the turbocharger performance at low rotational speeds, developing a method to predict the turbine and compressor performance in non-adiabatic conditions. Chapman et al. [9] developed a finite element analysis of a turbocharger to determine the heat fluxes going through the main bodies. The results of this analysis showed that the external heat transfer from the turbine is two orders of magnitude larger than that occurring in the compressor. Bohn et al. [10] [11] and Heuer et al. [12] carried out an experimental and computational analysis on a turbocharger at different operating points. Beyond the standard measurements to determine the main performance parameters, the surface temperature of the turbine and the compressor casings were measured. These 
results were set as boundary conditions for a numerical calculation. A parametric study was carried out for different turbine inlet temperatures and mass flow rates. The results of the calculation used a one dimensional Nusselt number that enabled the prediction of heat transfer within the compressor. Although the heat transfer calculation through the proposed Nusselt number proved to be satisfactory for different operating conditions, the analysis did not lead to good agreement with experimental results when applied to different turbochargers. In order to get a good prediction, the Nusselt number had to be fitted with experimental results for each turbocharger [6]. Baines et al. [13] proposed a heat transfer network model of a turbocharger based on tests conducted on three different turbochargers. A set of heat transfer coefficient values was found using conventional convective heat transfer correlations. These coefficients showed to be independent of the turbocharger model, and the calculation of the heat transfer within the turbocharger could be performed with good approximation.

\section{BACKGROUND AND OBJECTIVES}

Aim of this research is to provide an insight into the heat transfer process occurring within a turbocharger. This analysis relies on the results of an experimental and computational analysis carried out at Imperial College London. A commercial turbocharger was installed on a 2.0 liter diesel engine and tested for a range of engine speeds and loads varying from 1000 from to $3000 \mathrm{rpm}$ and $16 \mathrm{Nm}$ to $250 \mathrm{Nm}$ respectively. Beyond the standard measurements necessary to determine the operating points of the compressor and turbine, the turbocharger was instrumented with additional thermocouples measuring the surface temperatures of the turbine and compressor casings in a number of points. The test results enable to quantify the heat fluxes through the turbocharger and to evaluate their impact on the compressor performance. Based on the experimental results a validated 1-D heat transfer model was then generated to predict the compressor non-adiabatic efficiency. By doing this it is then possible to assess the compressor non-adiabatic efficiency by mean of regression analysis. Regression analysis is used to predict a continuous dependent variable from a number of independent variables. In engineering it is usually adopted to determine the coefficients in problems related with forced convection. So far a similar approach has not been used to characterize the turbocharger performance. The main benefit of regression analysis is that the contribution of each parameter can rapidly be quantified. Potentially this could be very useful to turbine designers and software developers in the selection of turbochargers providing the best compromise in relation to the input parameters. However it 
must be considered that this method is valid and can be applied as long as experimental data can be used for model validation.

\section{NON-ADIABATIC EFFICIENCY}

In order to assess the effects of heat transfer on the compressor efficiency, in common with other researchers, the non-adiabatic efficiency is introduced [3]. This efficiency represents the apparent compressor efficiency measured under non-adiabatic operating conditions and it is defined as the ratio between the isentropic and the actual enthalpy rise:

$$
\eta_{\text {dia }, c}=\frac{\Delta h_{i s}}{\Delta h_{d i a}}=\frac{T_{2, i s}-T_{1}}{T_{2}-T_{1}}
$$

$\eta_{d i a, C}$ differs from the adiabatic efficiency in which the adiabatic enthalpy rise is taken into account:

$$
\eta_{a d i, c}=\frac{\Delta h_{i s}}{\Delta h_{a d i}}=\frac{T_{2, i s}-T_{1}}{T_{2, a d i}-T_{1}}
$$

As reported by Casey et al. [14] [15] the use of the isentropic enthalpy rise is not justified when dealing with heat transfer process. A reversible non-adiabatic flow is no longer isentropic and therefore it is inappropriate to use the isentropic process as the reference of the ideal work required by a perfect non-adiabatic compressor. In the work reported here, this consideration can in some way be bypassed when considering the actual compression process within the impeller $\left(1 * \rightarrow 2_{\text {adi }}\right)$ as if it was adiabatic. The external heat addition instead can then be split into two parts: the heat added before $\left(q_{c, \text { before }}\right)$ and after $\left(q_{c, \text { after }}\right)$ compression (Fig.1). In this way the initial and the final state of the compression are the same as those of a complete non-adiabatic process $(1 \rightarrow 2)$ and hence Eq. (1) can be used with no ambiguity ${ }^{2}$.

\section{EXPERIMENTAL INVESTIGATION}

\subsection{Experimental setup}

The following discussion provides essential information on the experimental facility layout. A schematic diagram of engine test rig is shown in Fig. 2 while in Fig. 3 a general

\footnotetext{
${ }^{2}$ The compressor efficiency in this paper is usually referred as relative efficiency: this is defined as the ratio between the compressor peak efficiency as per the cold map and the efficiencies measured under non-adiabatic conditions
} 
overview of the engine is also given. An eddy current dynamometer (Borghi \& Saveri FE260$S$ ) was used to keep the engine load constant at a desired value. The engine was connected to it via a Universal-Joint (U-J) shaft (Clarke Transmissions TRSZV131001). The dynamometer was water cooled with water passing inside the stator to dissipate the generated heat. The engine was air cooled by a $30 \mathrm{KW}$ water-to-air heat exchanger (AKG T4). Moreover, a standard air-to-air intercooler with minor modifications was used to cool the air just before the inlet manifold. The engine was operated via an instrumentation rack (Test Automation Ltd series 2000).

Figure 4 shows the instrumented turbocharger. In order to support the thermocouples on the turbine and compressor casings, two semi-circular plates were fixed onto the turbocharger and ceramic felt and washers were used to avoid conductive effects. Once the turbocharger was installed on the engine, two additional frames were added to support the isothermal connector strips. On overall the following measurements were taken:

- Inlet and exit air temperature and pressure to the compressor

- Inlet and exit exhaust gas temperature and pressure to the turbine

- Inner and outer casing temperatures of the compressor and turbine

- Surface temperature of the exhaust manifold and bearing housing

- Inlet and exit temperature of the cooling oil

- Air and oil flow rate

- Shaft speed

\subsection{Test conditions setup}

The turbocharger under study was tested at constant load points for a range of engine speeds and loads. Measurements were obtained for engine speeds between 1000 and 3000 rpm at a step of $500 \mathrm{rpm}$; for each engine speed the load applied was varied from 16 to 250 $\mathrm{Nm}$. The test conditions are summarised in Table 1.

\subsection{Experimental results}

\section{Surface temperature of the compressor and turbine casing}

The inner and outer wall temperatures of the turbine and compressor casings were measured at the Engine, Top and External side for each engine speed and load. Table 2 summarises the results for each engine speed. From Table 2 it can be seen that the surface temperatures of the compressor and turbine casings are not uniform; they tend to decrease 
substantially as one moves from the Engine side towards the External side. This can be attributed to the proximity of the turbocharger to the engine. This is shown in Table 2 by the temperature difference $\left(\Delta T_{E n g-E x t}\right)$ between the Engine and External positions. This temperature difference goes from a minimum of $10 \mathrm{~K}$ (for low engine speeds and load) to a maximum of $\approx 68 \mathrm{~K}$, measured at $2000 \mathrm{rpm}$ and $250 \mathrm{Nm}$. In Table 2 are also reported the wall temperatures difference $\Delta T_{W}$ across the turbine and compressor wall for every given reference position of the thermocouples. The temperature across the turbine wall decreases from the inner to the outer wall while the opposite occurs for the compressor. In Figs. 5 and 6 the wall temperature difference $\Delta T_{W}$ was plotted against the temperature of the exhaust gases for both the turbine and the compressor. From Fig. 5 it can be seen that the wall temperature difference on the External side (labelled as $\Delta T_{W t, \text { External }}$ ) is greater than that on the Engine side $\left(\Delta T_{W t \text { External }}\right)$. As the temperature of the exhaust gases increases $(\approx 950 \mathrm{~K})$ the discrepancy between $\Delta T_{W t \text { Engine }}$ and $\Delta T_{W t \text { External }}$ can go up to $40 \mathrm{~K}$. On the compressor side instead the temperature difference between the inner and the outer wall is greater on the Engine side than on the External side (Fig. 6). The measured $\Delta T_{W c \text {,Engine }}$ can be as much as ten times larger than $\Delta T_{W c, \text { External. }}$ For instance at $3000 \mathrm{rpm}$ and $200 \mathrm{Nm}, \Delta T_{W c \text {,Engine }}$ is $\approx 29 \mathrm{~K}$ while the corresponding $\Delta T_{W c \text {, External }}$ is $\approx 3 \mathrm{~K}$. A schematic diagram of the heat transfer process occurring within the turbine and the compressor casing is given in Figs. 7 and 8. The high temperature of the turbine casing causes the heat fluxes to be directed towards the surrounding environment while the opposite occurs on the compressor side where heat from the surrounding environment flows into the compressor.

\section{Cooling oil, bearing housing and exhaust manifold temperatures}

The inlet and exit oil temperatures for the bearing housing were measured together with the bearing housing surface temperature. The test results are shown in Fig. 9. The oil temperature varies from a minimum of $321 \mathrm{~K}$ at the inlet at $1000 \mathrm{rpm}$ to a maximum of $394 \mathrm{~K}$ at the exit at $3000 \mathrm{rpm}$. The bearing housing test results highlighted that its surface temperature closely follows that of the cooling oil temperature. The temperature difference $\left(\Delta T_{B H-o i l}\right)$ between the surface temperature of the bearing housing and the mean oil temperature (inlet to exit) is proportional with the temperature of the exhaust gases; for exhaust gas temperature $T_{E x h}=373 \mathrm{~K}$ the temperature difference $\Delta T_{B H \text {-oil }} \approx 5 \mathrm{~K}$ while as the exhaust gas temperature increases, $T_{E x h}=823 \mathrm{~K}$, the temperature difference $\Delta T_{B H \text {-oil }}$ goes up to $\approx 33 \mathrm{~K}$. The surface temperature of the exhaust manifold was also measured. Two surface thermocouples were placed on the pipes located underneath the compressor and the turbine. 
The measured temperatures are shown in Fig. 10 together with those of the exhaust gases. From Fig. 10 it can be seen that the difference between the surface temperature of the pipe on the turbine side and that of the exhaust gases varies from a few degrees at low loads up to around $130 \mathrm{~K}$ at higher loads. Such a temperature difference is even more severe for the pipe on the compressor side, where a maximum temperature drop of almost $200 \mathrm{~K}$ was measured.

One of the main challenges in engine calculations is the need to find a correlation for the compressor exit temperature for different operating conditions. This temperature represents a boundary condition for the combustion analysis in the engine cylinders and hence if it was possible to establish a unique correlation between the exhaust gases and the compressor exit temperatures, it would then be possible to calculate the compressor nonadiabatic efficiency. A solution to this issue is proposed here.

In the standard turbochargers configuration, the bearing housing is directly coupled to the compressor casing through a plate bolted on to the so called compressor back-plate, see Fig. 13. If one assumes that all of the heat transferred to the air after compression is transferred through the compressor back-plate, then the plate temperature is equal to the surface temperature of the bearing housing, and Eq. (3) becomes:

$$
\dot{Q}_{f c}=h_{\text {air }} A_{B P}\left(T_{B H}-T_{2 *}\right)=\dot{m}_{\text {air }} c_{p}\left(T_{2 *}-T_{2}\right)
$$

By solving for $T_{2}$, one obtains Eq. (4).

$$
T_{2}=T_{2 *}+\frac{\dot{Q}_{f c}}{\dot{m}_{\text {air }} c_{p}}=T_{2 *}+\frac{h_{a i r} A_{B P}}{\dot{m}_{\text {air }} c_{p}}\left(T_{B H}-T_{2 *}\right)
$$

All the terms of Eq. (4) are known except $T_{2 *}$ and $T_{B H}$. The former can be derived considering the non-adiabatic compression process of Fig. 1. Here the heat transfer process was simplified into three paths $\left(1 \rightarrow 1^{*}, 1^{*} \rightarrow 2^{*}, 2^{*} \rightarrow 2\right)$. In reality only a small amount of heat is transferred before compression, since the incoming air goes through a very short passage (inducer inlet pipe). Hence the temperature $T_{2 *}$ can be assumed to be similar to the temperature $T_{2 a d i}$ that would occur if the compression process was fully adiabatic $\left(1 \rightarrow 2_{a d i} \rightarrow 2\right)$, as given in Eq. (5).

$$
T_{2 *} \cong\left(T_{2, a d i}\right)=T_{1}\left[1+\left(\frac{P R^{\gamma-1} / \gamma}{\eta_{C, a d i}}\right)\right]
$$


For $T_{B H}$ instead we can refer to the experimental results of Figs. 11 and 12 . The exit temperature to the compressor seems to exhibit a linear trend with the temperature of the exhaust gases (dashed red line in Fig. 12). Such a trend was also observed for the surface temperature of the bearing housing for which the test measurements showed that $T_{B H}$ and the temperature of the exhaust gases are linearly related (dashed red line in Fig. 11). Therefore since the temperature of the exhaust gases is known, it is possible to correlate the temperature of the bearing housing to the temperature of the exhaust gases as follows:

$$
T_{B H}=\left(T_{a m b}+b\right)+g_{r a d} T_{e x h}
$$

where $g_{\text {rad }}$ is the gradient of the trend line. By including Eq. (5) and Eq. (6) into Eq. (4), the exit temperature to the compressor $\left(T_{2}\right)$ under non-adiabatic conditions can be calculated as given in Eq. (7).

$$
\begin{aligned}
T_{2}=T_{1}[1 & \left.+\left(\frac{P R^{(\gamma-1)} / \gamma}{\eta_{C, a d i}}\right)\right] \\
& +\frac{h_{a i r} A_{B P}}{\dot{m}_{\text {air }} c_{p}}\left\{T_{1}\left[1+\left(\frac{P R^{(\gamma-1)} / \gamma}{\eta_{c, a d i}}\right)\right]-\left[\left(T_{a m b}+b\right)+g_{\text {rad }} T_{\text {exh }}\right]\right\}
\end{aligned}
$$

The outcomes of Eq. (7) are shown in Fig. 11, in which the measured and the calculated compressor exit temperatures are reported; their absolute deviation is also shown. The overall agreement of the computed temperatures is good over the whole range of test conditions. The absolute deviation between the predicted and measured temperatures is no bigger than $2 \%-3 \%$. Such a deviation remains slightly over the uncertainty range associated with thermocouples, indicated by a dashed black line in the same figure.

\section{Compressor non-adiabatic efficiency and exit flow temperature}

The measured non-adiabatic compressor performance was compared with that extrapolated by the cold compressor maps provided by the manufacturer. From Fig. 12 it can be noticed that the overall deterioration of the compressor efficiency in hot conditions is severe over the whole range of temperatures of the exhaust gases. This is well shown in 
Table 3 where the compressor efficiency in adiabatic and non-adiabatic conditions is given. The absolute relative deviation ${ }^{3} \Delta \eta$ between the efficiencies goes from a minimum of $\approx 17 \%$ to a maximum of $\approx 30 \%$. The scatter of the compressor non-adiabatic efficiencies as the exhaust gas temperature increases seems to suggest that there is no direct correlation between the two. In fact one would expect that the deterioration of the efficiency increased with an increase of the exhaust gas temperature at the turbine entry. This is not always the case since the compressor efficiency in non-adiabatic conditions, besides being dependent on the exhaust gas temperature, is also affected by other physical properties like the mass flow rate and the rotational speed.

\section{HEAT TRANSFER MODEL}

This section describes the outcomes of a 1-D heat transfer model. The implementation of heat transfer models for turbochargers involves the quantification of a large number of parameters that complicates the analysis. Here we tried to simplify the approach. A detailed quantification of the heat transfer process within the turbocharger would require a full 3-D conjugate heat transfer analysis. In the model described below, the heat fluxes through the turbocharger were evaluated by means of well known correlations available for heat conduction, radiation and convection. The process was validated against experimental data.

\subsection{Turbocharger Model}

A reduced order turbocharger model developed consisting of an assembly of bodies of known geometry parameters. Such simplified model was obtained by means of progressive steps: firstly a full 3D-CAD model of the turbocharger was developed and then by analysis of the overall turbocharger configuration, the geometry was simplified to an assembly of three cylindrical bodies representing the turbine, the bearing housing and the compressor scroll (refer to Fig. 13-a and b).

Fig. 14 shows the cross section of the 1-D model together with the main heat transfer paths. The exhaust gases coming from the combustion flow into the turbine, exchange heat by forced convection to the turbine casing and to the bearing housing $\left(Q_{t \rightarrow B H}\right)$. Due to the gradient existing between the inner and outer surface of the turbine casing, heat is conducted through the wall and dissipated by radiation $\left(Q_{t, \text { rad }}\right)$ and free convection $\left(Q_{t, \text { conv }}\right)$ to the surrounding environment. At the same time, the air that flows through the rotor expands and,

\footnotetext{
${ }^{3}$ Relative deviation defined as: $\Delta \eta=\left[1-\left(\eta_{\text {adi,c }} / \eta_{\text {dia,c }}\right)\right]$
} 
as a consequence the pressure drops and the temperature decreases; heat transfer occurs to the blades and subsequently to the shaft. The turbine exit temperature is therefore calculated as the sum of the temperature drop due to the expansion and the heat transferred to the shaft $\left(Q_{t \rightarrow S}\right)$. In the bearing housing the heat is dissipated by forced convection to the oil $\left(Q_{o i l \rightarrow B H}\right)$, and through free convection $\left(Q_{B H, c o n v}\right)$ and radiation $\left(Q_{B H, r a d}\right)$ to the environment. In the shaft, the heat is dissipated only by forced convection to the oil $\left(Q_{S \rightarrow \text { oil }}\right)$; note that the heat generated by friction within the bearing housing is not considered here. While the gases expand in the turbine, cold air flows into the compressor. The inlet air is heated up by the shaft $\left(Q_{S \rightarrow \text { air }}\right)$ and compressed in the impeller with a consequent rise in temperature and pressure. After the compression, the air flows into the diffuser, where the gas is further heated up by forced convection to the back-plate $\left(Q_{c \rightarrow a i r}\right)$, natural convection $\left(Q_{c, c o n v}\right)$ and radiation $\left(Q_{c, r a d}\right)$.

\subsection{Model Flow Chart}

Figure 15 provides the flow chart of the model. The input parameters for the turbocharger model are the performance parameters extrapolated by the "cold" maps, the oil flow rate and the temperature of the exhaust gases. The control parameter for the whole calculation is the temperature of the exhaust gases leaving the turbine $\left(T_{04}\right)$. In order to start the calculation an initial assumption on the exit temperature of the exhaust gases $\left(T_{04}\right)$ and the heat added before compression $\left(q_{c, \text { before }}\right)$ and expansion $\left(q_{t, \text { before }}\right)$ was made. With the initial estimated values of $q_{c, \text { before }}$ and $q_{t, \text { before }}$ the heat fluxes going through the turbocharger can be evaluated. On the basis of the calculation, a new evaluation for $q_{c, \text { before }}$ and $q_{t, b e f o r e}$ is made according from the newly computed temperatures. These two new values for the heat transfer are compared with those calculated initially and if the convergence is not satisfied, a new estimation for $q_{c, \text { before }}$ and $q_{t, \text { before }}$ will be made until the convergence is satisfied. As with the heat, the exit temperature to the turbine $\left(T_{04}\right)$ and the compressor $\left(T_{02}\right)$ are calculated and a comparison is then made between two consecutive values until convergence is satisfied. Once the calculation is converged, the non-adiabatic efficiencies are finally computed.

\subsection{Model Validation}

The simulation results are compared with those obtained through experimental results. Additionally, the capability of the model to capture the effects of heat transfer for different rotational speeds and temperatures of the exhaust gases was also evaluated. Four rotational speeds were selected from the compressor cold maps and input into the model together with 
four different temperatures of the exhaust gases. The non-adiabatic efficiency maps could then be generated and the data used for statistical analysis.

\section{Heat conducted through the turbine casing}

The heat flux through the turbine casing represents the amount of heat that is dissipated by the gas before expanding in the rotor. A good evaluation of the heat conducted is therefore important to the overall success of the simulation. The heat conducted through the turbine casing in the three measuring locations (Engine, Top and External side) is given in Fig. 16. Due to the large scatter of the calculated points, a zone of actual heat conduction was drawn to aid comparison. The averaged values for the heat conducted in the three measuring locations was then calculated (blue diamonds) together with the best fit line (solid blue curve). Despite the simplicity of the turbocharger model, the computed heat conduction (solid red line) falls well within the actual heat conduction area. The model prediction follows the measured trend line with reasonable accuracy. Although the discrepancy between calculated and measured values can go up to $\pm 18 \%$, the overall averaged deviation over the entire range of exhaust gas temperatures remains low, (refer to Table 4). This seems to confirm the effectiveness of the assumptions made on the set up of the turbocharger model, particularly if one considers the large range of temperatures evaluated $(\approx 450 \mathrm{~K}$ to $\approx 950 \mathrm{~K})$ and also the significant assumptions made on the geometry of the turbocharger. The calculated deviation can be attributed to several factors. First of all, the simplified geometry of the model does not take into account the fact that the turbine casing comes as a whole die cast body with the exhaust manifold. This leads to a temperature distribution difficult to predict locally. Another factor contributing to the overall deviation is that, within the model the wall thickness of the turbine was assumed to be uniform. This is not the case since the wall thickness of turbine housing varies a consequence of the manufacture process and design requirements.

\section{Compressor exit temperature and non-adiabatic efficiency}

The outcomes of the model prediction for the compressor exit temperature and compressor non-adiabatic efficiency is reported here. Table 5 shows the computed values for the compressor efficiency and exit temperature compared with the experimental results. The simulation results are plotted in Fig. 17 where the compressor adiabatic efficiency and the corresponding exit temperature are also included for comparison.

From Fig. 17, it can be noticed that the model prediction for the compressor exit temperature is very good. The predicted exit temperatures closely follow those measured 
experimentally, with a difference no larger than few degrees. The absolute difference (refer to Table 5) for the predicted exit temperatures is not larger than $5 \mathrm{~K}$ and on the overall the averaged deviation from the experimental data is $\approx 2.5 \mathrm{~K}$. This is only slightly above the uncertainty range associated with experimental measurements and it shows the effectiveness of the assumptions made on the model geometry and the occurring heat fluxes. Nevertheless, such a good prediction does not correspond to an equally good prediction for the compressor efficiency. On the efficiency side the model prediction seems to be less accurate than that exhibited for the temperature. The scatter of data of the computed efficiency from that measured experimentally remains within $\approx 3$ percentage points for most of the operating conditions considered here. This can mainly be attributed to the error propagation associated with the computed exit temperature that makes the predicted non-adiabatic efficiency to deviate more from that measured experimentally. However, on the overall, the prediction for the compressor non-adiabatic efficiency remains within an acceptable range and it enables to extend our simulation to different operating conditions with good degree of confidence.

\section{Model qualitative validation}

As the experimental data was obtained on a turbocharger installed on a real engine, it was not possible to control all the turbocharger parameters so as to obtain a wide range of pressures. In order to overcome such a limitation, the performance parameters from the turbocharger cold maps were extrapolated for four different rotational speeds. For each of these, the non-adiabatic efficiencies were calculated for five different temperatures of the exhaust gases as given in Table 6. The outcomes of the model calculation are given in Figs. 18 to 21 . The compressor non-adiabatic efficiency and the corresponding exit temperatures are reported against the mass flow rate for each condition of Table 6.

From Figs. 18 to 21, it can be seen that the efficiency drop associated with increasing heat transfer is very well captured by the model. At high rotational speed the predicted compressor efficiency does not deviate substantially from that measured in cold conditions. This is clearly seen in Fig. 18 where at 163.3 revs $/ \sqrt{\mathrm{K}}$ and $T_{E x h}=550 \mathrm{~K}$, the efficiency drop is only $\approx 3 \%$ while it goes up to $\approx 10 \%$ for $T_{E x h}=950 \mathrm{~K}$. This is fully consistent with the experimental findings [4], for which it was found that at high rotational speeds the effects of heat transfer on compressor performance is negligible. The experimental evidence also showed that as the rotational speed drops to low values, the temperature effect becomes dominant. This is also well captured by the model. In fact, as the temperature increases, the compressor performance decreases consistent with experimental evidence. At high rotational 
speeds for which the temperature effect on the compressor performance is not important, the predicted non-adiabatic efficiencies do not vary substantially to one another (Figs. 18 and 19). At $550 \mathrm{~K}$ the computed exit temperature to the compressor is almost equivalent to that calculated in adiabatic conditions. As the temperature of the exhaust gases increases $(550 \mathrm{~K}$ to $950 \mathrm{~K}$ ), the temperature rise to the compressor varies by only $\approx 10 \mathrm{~K}$. On the contrary, at lower rotational speeds (Figs. 20 and 21) the effect of temperature on efficiency is more relevant and this corresponds to large variation in the compressor performance as the temperature increases.

\section{STATISTICAL ANALYSIS}

In order to complete the analysis on heat transfer, the data generated by the model was used to assess the compressor non-adiabatic performance by means of a regression analysis. In order to perform the regression analysis, the following steps were taken:

1. Identify the minimum number of parameters that better describe the compressor efficiency in non-adiabatic conditions,

2. Perform the multiple regression analysis, determine the regression coefficients and evaluate the goodness of fit through the evaluation of conventional fit parameters,

3. Discuss the consistency of the regression response with the experimental findings and assess the capability of the statistical approach for the calculation of the compressor efficiency.

\subsection{Parameters definition}

In order to run a statistical analysis a number of significant parameters, responding to Eq. (8), must be identified.

$$
\eta=f\left(x_{i}\right)
$$

where $x_{i}$ are the explanatory variables (independent parameters) and $\eta$ is the response variable. In a compressor map, a given point is uniquely defined by a pair of non-dimensional parameters selected amongst efficiency, pressure ratio, mass flow and speed. For the purpose of this research the pressure ratio $P R$ and the rotational speed given in terms of Mach number were selected. However a third parameter accounting for the heat transferred to the 
compressor must be included in the analysis. This was identified in the form of "temperature parameter". A more detailed description of the parameters can be found below:

1. Pressure ratio $(P R)$ : in order to determine a point in a conventional compressor map, at least two parameters must be known. The pressure ratio was identified as an independent parameter. It is defined as the ratio between the stagnation pressures at the inlet and exit to the compressor as given in Eq. (9):

$$
P R=P_{02} / P_{01}
$$

2. Mach number $(M)$ : this is the local Mach number at the exit to the impeller blade row. The compressor impeller used for the current research has backward swept blades (blade angle $\beta_{B 2}=-50^{\circ}$ ) and the velocity triangle is given in Fig. 22. The ideal case of a perfectly guided flow for radial blades was also considered here in order to quantify the effects of blade geometry and slip on the overall compressor performance. The absolute velocities for both the backward swept and radial blade impeller can be calculated as given in Eq. (10) and Eq. (11).

$$
\begin{aligned}
& C_{2, a d i}=\sqrt{\left(\mu U_{2}+C_{2 m, a d i} \tan \beta_{B 2}\right)^{2}+C_{2 m, a d i}^{2}} \\
& C_{2, a d i}=\sqrt{U_{2}^{2}+C_{2 m, a d i}^{2}}
\end{aligned}
$$

where $U_{2}$ is the tangential velocity, $C_{2 m, a d i}$ the meridional component of the absolute velocity and $\mu$ the slip factor calculated with the Stanitz correlation [16]. The Mach number is then given in Eq. (12):

$$
M_{2, a d i}=\frac{C_{2, a d i}}{\sqrt{\gamma R T_{2, a d i}}}
$$

Shabaan et al. [3] demonstrated that the parameters that are relevant to the heat transfer process within a compressor are the peripheral Mach number $\left(M_{2 u}=U_{2} / \sqrt{\gamma R T_{01}}\right)$, the 
flow coefficient $\left(\varnothing=C_{2 m \text {,adi }} / U_{2}\right.$ ), the slip factor $\mu$ and the blade angle at the impeller outlet $\left(\beta_{B 2}\right)$. It can be demonstrated that the local Mach number $M_{2, \text { adi }}$ is a function of all the parameters indicated above and it can be developed to yield to Eq. (13):

$$
M_{2, a d i}=\sqrt{\frac{2 M_{2 u}^{2}\left(\emptyset^{2}+\lambda^{2}\right)}{2+\left[(\gamma-1) M_{2 u}^{2}\left(2 \lambda-\emptyset^{2}-\lambda^{2}\right)\right]}}
$$

where

$$
\lambda=\frac{C_{\theta 2}}{U_{2}}=\frac{\mu}{\left[1-\left(\tan \beta_{B 2} / \tan \alpha_{2}\right)\right]}
$$

$\lambda$ is defined as the work input factor [17] and for $\lambda=1, C_{\theta 2}=U_{2}$, and Eq.(13) reduces to the particular case of a perfectly guided radial blade impeller:

$$
M_{2, a d i}=\sqrt{\frac{2 M_{2 u}^{2}\left(\emptyset^{2}+1\right)}{2+\left[(\gamma-1) M_{2 u}^{2}\left(1-\emptyset^{2}\right)\right]}}
$$

Eq. (13) and Eq. (15) were obtained for backward swept (with $\mu \neq 0$ ) and radial blade impeller (with $\mu=0$ ). From Eq. (13) it can be seen as $M_{2, \text { adi }}$ contains the effects of the main parameters involved in the heat transfer process. The benefit of using the local Mach number is that it reduces the number of variables to be used in a parametric analysis, thus simplifying the calculation of the compressor non-adiabatic performance.

3. Temperature parameter (TP): this parameter was introduced in order to take into account the effects of heat transfer on the compressor efficiency. The heat transferred within a turbocharger is mainly generated by the exhaust gases entering the turbine. After exchanging heat with the turbine housing, the flow will then expand in the rotor leaving the turbine with lower temperature $\left(T_{04}\right)$. On the compressor side instead, heat from the turbine to the compressor is mainly transferred through the bearing housing that in turn will cause a rise in the compressor exit temperature $\left(T_{02}\right)$. We can then infer that the exit temperatures to both the compressor and the turbine are associated with the heat exchanged within the turbocharger and therefore the ratio between $T_{02}$ and $T_{04}$ was included in the regression analysis as a non- dimensional parameter, as given in Eq. (16). 


$$
T P=\frac{T_{04}}{T_{02}}
$$

\subsection{Multiple regression analysis}

After having defined the $x_{i}$ explanatory variables, Eq. (17) assumes the form:

$$
\eta=f(P R, M, T P)
$$

The general computational problem that needs to be solved in multiple regression analysis is to fit a line to a number of points. In the multivariate case, when there is more than one independent variable, the multiple regression procedure will estimate a linear equation of the form:

$$
\eta=A_{0}+A_{1} P R+A_{2} M+A_{3} T P
$$

The expression in Eq. (18) is ready for multiple regression operation, with pressure ratio parameter $(P R)$ which required a logarithmic transformation since a certain skewness was observed in the plot of residuals.

Prior to the multiple regression analysis, the single linear regression analysis for each explanatory variable was performed. The results of regression are reported in Table 7 which contains the essential statistics that help explain the obtained coefficient. The squared value of the Mach number was also included as an additional since the regression response $(\eta)$ is expected to have some curvature given that the compressor efficiency curve usually shows a parabolic trend.

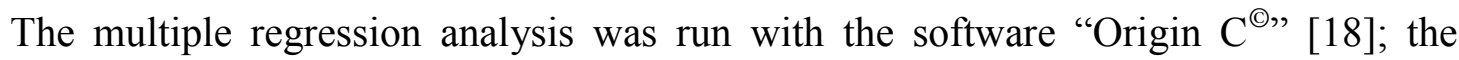
results for both backward swept and radial blade impeller are provided in Table 8 . The final expression for Eq. (18) is given in Eq. (19) and Eq. (20):

$$
\begin{aligned}
& \eta_{c_{b s}}=-0.04158 T P+0.12336 \log (P R)+1.15921 M_{b s}-0.43205 M_{b s}^{2} \\
& \eta_{c_{r}}=-0.04397 T P+0.19304 \log (P R)+0.89422 M_{r}-0.28415 M_{r}^{2}
\end{aligned}
$$


It is worth noting that no constant is present in Eq. (19) and Eq. (20), $C_{0}=0$. This was purposely set equal to 0 since no efficiency is expected to exist if no flow is going through the compressor $(P R=1, M=0)$.

\subsection{Discussion of results}

The linear regression analysis for the single explanatory variables shows that these are strongly correlated with the efficiency given that the p-value is smaller than $0.0001^{4}$. This supports the assumption of significant relationship existing between $\eta$ and the explanatory variables.

Proven the statistical significance of the explanatory variables, the goodness of fit of Eq. (19) and Eq. (20) with $\eta$ must also be checked by looking at the adjusted $\mathrm{R}^{2}$ value. The adjusted $\mathrm{R}^{2}$ is $\approx 0.9$ for both Eq. (19) and Eq. (20). Such a high value is in favor of the goodness of fit and it seems to support the assumptions made on the compressor nonadiabatic efficiency and on the effectiveness of the regression analysis as a predictive tool.

After having verified that the selected explanatory variables are statistically significant, their significance under a physical point of view must also be assessed:

- Temperature parameter $\left(T P^{5}\right)$ : the temperature parameter shows the smallest coefficient in respect to the other explanatory variables, $P R$ and $M$. This means that the effects of the temperature rise within the turbocharger are overcome by the aerodynamic effects as the pressure ratio and the Mach number increase. In addition to this, the regression coefficient also exhibits a negative value. This suggests that, for a fixed $P R$ and $M$, an increase in $T P$ corresponds to a decrease in efficiency.

- Pressure ratio $(\log P R)$ : the pressure ratio is one of the two independent parameters extrapolated from the compressor map. The pressure ratio appears in logarithmic form in both Eq. (19) and Eq. (20). This was made necessary because of the skewness exhibited by the histogram of residuals although this choice also owns a physical reason. In the case where the pressure ratio is equal to 1 this implies that no flow is going through the machine and that no work is produced. Hence the efficiency is equal to 0 . The logarithm of $P R$ takes into account this feature.

\footnotetext{
${ }^{4}$ In regression analysis the p-value represents the probability that the coefficient of a variable is non zero.

${ }^{5}$ From now on when referring to the TP contribution to the compressor performance, this must be considered as a negative contribution leading to efficiency drop.
} 
- Mach number $(M)$ : this parameter is present both in linear and quadratic form. The regression coefficient for $M$ is the biggest in both Eq. (19) and Eq. (20). This means that the compressor performance is strongly dependent on the Mach number and that the effects of the heat transfer diminish as the rotational speed increases. Again this is consistent with the experimental findings [4] which showed that there is no significant difference between the adiabatic and the non-adiabatic compressor performance at high rotational speeds.

It must be mentioned that looking at the magnitude of the regression coefficients does not help to give their real contribution to the overall compressor performance. Each term of Eq. (19) and Eq. (20) is given by the combination of the regression coefficients and the explanatory variables. Therefore, it is necessary to look at the range into which the explanatory variables vary in order to assess their contribution to the compressor efficiency. Typical values for $M, \log P R$ and $T P$ are given in Table 9 . The explanatory variable $M$, despite showing a large value of the regression coefficient, varies within a small range (0.5 to 1.2). The opposite occurs for the temperature parameter for which the small contribution given by its regression coefficient is in somehow compensated by a larger value of $T P$.

In Fig. 23, a 3-D plot of the contribution (in percentage points) of each parameter to the compressor non-adiabatic efficiency is given for both the backward swept and radial blade impeller. The Mach number is by far the most significant parameter and its value remains above $70 \%$ for the whole range of speeds and temperatures. The temperature parameter $T P$ decreases with speed while the opposite occurs for PR. In Fig. 24 this is even more evident. The explanatory variables were plotted against the rotational speed and each point in the plot represents the average value of the corresponding parameter over the whole range of exhaust gases temperatures $(550 \mathrm{~K}$ to $950 \mathrm{~K})$. Although the average is not entirely representative of the $T P$ values (for which the temperature change has a large impact) this does not largely affect $M$ and $P R$. From Fig. 24 it can be gathered that the Mach number accounts for the largest portion of the compressor non-adiabatic efficiency. Its trend remains fairly constant across the entire speed range meaning that its weight on the overall compressor efficiency is almost independent on speed (see Table 10). $T P$ and $P R$ instead represent a smaller portion of the efficiency. $T P$ exhibits a decreasing trend with speed and at high speeds it is no larger than $\approx 10 \%$. This is more evident in Fig. 25 where $T P$ was plotted against temperature for constant speed lines. 
In Figs. 23 and 24 the effect of geometry on the explanatory variables is also given. For the backward swept blade impeller, the contribution of the Mach number $M_{b s}$ remains above that of the radial impeller $M_{r}$. The reason is found in the deviation of the absolute velocity $\left(C_{2, \text { adi }}\right)$ from the perfectly guided flow conditions and hence in a lower value of the Mach number (refer to Fig. 22). On the other hand, the pressure ratio $P R_{r}$ for the backward swept blade impeller compensates for such a deficit of the Mach number $\left(M_{r}\right)$ and therefore the calculated values of $P R_{r}$ are bigger than those calculated for the back swept $\left(P R_{b s}\right)$. In Table 10 a quantification of the impact of geometry on the explanatory variables is provided.

The Mach number difference $\Delta M$ goes from $\approx 3 \%$ to $\approx 6 \%$ (in absolute value) as the speed increases. Such a difference is partly compensated by the pressure ratio for which values of $\triangle P R$ not larger than $\approx 4 \%$ were calculated (in absolute value). No variation instead was observed for the temperature parameter $T P$ that remains unchanged over the whole range of speeds. This suggests that $T P$ is insensitive to the geometry and it can be readily explained by looking at the definition of $T P$ in which no geometry parameter is present.

\subsection{Geometry effects on heat transfer}

The current research was based on the test data available for a single turbocharger. Even though the validity of the analysis remains unaltered, this would imply that this analysis is insensitive to the turbocharger size. This is not the case in reality as the heat transfer occurring within a turbocharger strongly depends on the geometry of the bodies involved in it. In order to quantify what is the impact of geometry on the compressor performance, two parameters were identified as the most significant on heat transfer: the compressor casing diameter $(D)$ and the distance between the compressor and the turbine, here defined as bearing housing length $(B H L)$ :

1. Bearing housing length (BHL): heat from the turbine side travels through the bearing housing towards the compressor. This parameter is mainly denoting the space available for the heat transfer dissipation by convection in the oil bearing assembly.

2. Compressor casing diameter $(D)$ : the air within the compressor is mainly heated up by forced convection with the casing. The size of the compressor casing is therefore crucial to determine the surface area available to the flow for heat exchange. 
A non-dimensional parameter, defined as the ratio between $B H L$ and $D$, was then introduced in the regression analysis:

$$
L D=\frac{B H L}{D}
$$

Since no experimental data were available, $B H L$ and $D$ were scaled by $\pm 15 \%, \pm 30 \%$ from those of the turbocharger previously studied. Different values of $L D$ were calculated by scaling alternatively $B H L$ and $D$. These are reported in Table 11 . The first row was obtained by fixing $D$ to its original value and scaling $B H L$. The opposite was done in the second row. The model was then run for the same range of speeds and temperatures as in Table 6 and the impact of $L D$ on the compressor efficiency was then assessed. The regression equation including $L D$ is given in Eq. (22). By the analysis of Eq. (22), it can be inferred that the impact of geometry on the overall compressor performance is not small. The regression coefficient for $B H L$ is significant, if compared to the others, and its contribution to the compressor efficiency ranges between $\approx 1 \%$ and $\approx 2.4 \%$, as reported in Table 11 .

$$
\eta_{c}=+0.01756 L D-0.05208 T P+0.40201 \log (P R)+1.5556 M-0.96984 M^{2}
$$

In Fig. 26 the variation of $L D$ is plotted against its contribution to the overall efficiency. It can be noticed as the impact of $L D$ on the compressor efficiency increases with $L D$. This suggests that $B H L$ and $D$ are inversely related to each other. An increase in $B H L$ is beneficial to the compressor efficiency since a lower amount of heat is transferred to the compressor. On the other hand, the role played by $D$ on the compressor efficiency is less clear. In fact, a decrease in $D$ corresponds to a reduced amount of surface area available to the flow for heat exchange.

\section{$7 \quad$ CONCLUSIONS}

This paper reported the outcomes of the investigation on heat transfer in turbochargers. The turbocharger under study was tested at constant load points for a range of engine speeds. Measurements were obtained for engine speeds between 1000 and $3000 \mathrm{rpm}$ at a step of $500 \mathrm{rpm}$; for each engine speed the load applied was varied from 16 to $250 \mathrm{Nm}$. The surface temperatures of three main bodies constituting the turbocharger (turbine and compressor casing, bearing housing) were measured in 17 stations. 
The test results showed that the engine has a large impact on surface temperature of the turbine and compressor casing and also that the surface temperatures of both the turbine and the compressor vary linearly with the temperature of the exhaust gases. A temperature gradient was also measured between the inner and the outer wall: on the turbine side this moves outward while the opposite occurs for the compressor. The surface temperature of the bearing housing was found to vary consistently with that of the cooling oil, with a temperature difference of about $\approx 30 \mathrm{~K}$. Similar trend to that of the bearing housing and the oil was found for the surface temperature of the exhaust manifold, with a temperature difference of up to $\approx 130 \mathrm{~K}$ on the turbine side. The compressor non-adiabatic efficiency was also evaluated; the deviation from that measured under adiabatic conditions goes from $17 \%$ to $30 \%$ as the rotational speed and air flow rate decreases. Based on the experimental results, an experimental correlation linking the compressor exit temperature with the exhaust gas temperature was proposed; the calculated temperature was found to agree well with the experimental results with a discrepancy no larger than $3 \%$.

A 1-D model of the turbocharger was developed and validated against the experimental results. The validation against test results showed that the trend of the heat transferred through the turbine casing is well captured; the compressor exit temperature could be predicted with an uncertainty no greater than $5 \mathrm{~K}$ while an averaged deviation of about $3 \%$ was found for the compressor non-adiabatic efficiency.

Based on the maps generated by the model, a multiple regression analysis was carried out for the compressor non-adiabatic efficiency. In this analysis, the following explanatory variables were chosen: absolute compressor exit Mach number $\left(M_{2, a d i}\right)$, the compression ratio $(P R)$ and the temperature parameter $(T P)$. The high values of the adjusted $\mathrm{R}^{2} \approx 0.9$ showed that the compressor non-adiabatic efficiency can be fitted with good degree of approximation by means of the selected parameters. The Mach number was found to contribute for $\approx 80 \%$ of the overall efficiency, the temperature parameter for $\approx 20 \%$ while the pressure ratio only few percentage points. The impact of the geometry on the compressor non-adiabatic efficiency was also assessed; this was found to account for about $\approx 2 \%$ of the overall compressor efficiency.

\section{ACKNOWLEDGEMENTS}

The authors would like to acknowledge Ricardo plc, Ford Motor Company Ltd and University of Brighton. This consortium along with Imperial College is part of a funded program (TSB-UK) named VERTIGO (Virtual Emission Research Tools and Integration). 
Furthermore the authors would also like to acknowledge Mr. Benjamin Kumm and $\mathrm{Mr}$. Katopodis Spyridon whose previous research at Imperial College was essential for the outcome of this paper.

\section{APPENDIX: MODEL EQUATIONS}

In order to calculate the heat fluxes through the turbocharger, the three main mechanisms of conduction, radiation and convection were considered. For the first two mechanisms Eq. (23) and Eq. (24) were applied to the surfaces involved with such heat transfer effects [19].

$$
\begin{aligned}
& \dot{Q}_{\text {cond }}=-k A \frac{d T}{d x} \\
& \dot{Q}_{\text {rad }}=-\sigma A\left(T_{\text {surf }}^{4}-T_{a m b}^{4}\right)
\end{aligned}
$$

For forced convection instead, the heat flux calculation is more complex. This has been calculated considering the Newton's Law of Cooling $\left(\dot{Q}_{c o n v}=h A \cdot \Delta T\right)$ and the procedure followed is outlined below.

\section{Heat transfer coefficients}

Heat transfer correlations need to be applied to evaluate the heat transferred coefficients caused by natural and forced convection. Heat transfer coefficients equation change according to the geometry of the body involved in the heat transfer process. For the particular case under study, different heat transfer coefficients need to be considered for the turbine, bearing housing, compressor casing and cooling oil. Below are given some of the correlations included in the model:

-Turbine casing: in the turbine casing have been considered three surfaces transferring heat [20], [21]:

1. the annular surface (Eq. 25)

2. both ends of the cylinder (Eq. 26)

$$
\begin{aligned}
h_{t, \operatorname{surf} 1} & =0.667 \frac{k_{T}}{D_{T}}(R a)^{0.25} \\
h_{t, \text { surf } 2} & =0.530 \frac{k_{T}}{D_{T}}(R a)^{0.25}
\end{aligned}
$$


-Bearing housing surface: the heat transfer on the bearing housing is similar to that on the annular surface of the turbine casing with the main difference that unlike the turbine casing (where the surface was treated as isothermal) the heat transfer coefficient in the bearing housing varies in the axial direction [22].

-Compressor casing: the compressor casing was modeled as a disc (in the paper referred as compressor Back-Plate) with the internal diameter equal to the external diameter of the bearing housing. The temperature was assumed to vary only along the radius. Similarly to the turbine round plate, the same correlation for the Nusselt number and the heat transfer coefficient was included in the model ${ }^{6}$ :

$$
h_{B P, \operatorname{surf}}=0.667 \frac{k_{B P}}{D_{B P}}[\operatorname{Ra}(y)]^{0.25}
$$

-Compressor and turbine: on the inside of the compressor and turbine volute, there is significant forced convection. The volute is modelled as a straight pipe and the heat transfer coefficient can be calculated from the Nusselt number when $\mathrm{D} / 2$ is chosen for the characteristic length.

$$
h_{T, C}=N u \frac{2 k}{D}=0.046 \frac{k}{D}=0.046 \frac{2 k}{D} \operatorname{Re}^{0.8} \operatorname{Pr}^{0.4}
$$

\section{Temperature distribution and heat fluxes calculation}

The next step involved is the evaluation of the temperature distributions in the turbine casing, the shaft, the bearing housing and the compressor casing. For reasons of space only the shaft case will be provided here [23].

-Shaft: The radial variation of the temperature was omitted since the shaft has a small diameter and high thermal conductivity; hence the temperature difference along the radius is lower than the axial temperature variation. In addition to this, the internal energy was considered to be constant since the model was developed as steady state. The energy balance for an infinitesimal element of the shaft then simplifies to Eq. (29) and it is shown in Fig. 27:

$$
\dot{Q}_{x}=\dot{Q}_{x+d x}+\dot{Q}_{S \rightarrow o i l}
$$

\footnotetext{
8 Please note that the y direction in the Eq. (27) was introduced to show that the compressor back-plate is normal to the axial direction of the turbocharger. The addition of an extra frame of reference might lead the reader to consider the model solution as a 2-D problem. This is not the case as the heat transfer model remains unaltered and it lies on the assumption of 1-D analysis.
} 
The term $\dot{Q}_{x+d x}$ can be expressed by use of the Taylor and the heat transferred to the oil $\left(\dot{Q}_{S \rightarrow \text { oil }}\right)$ and the axial derivative of the conductive heat flux can be rewritten by mean of Fourier's law. This leads to Eq. (30) for the axial distribution of heat along the shaft:

$$
\frac{d^{2} T_{S}(x)}{d x^{2}}-\frac{4 h_{\text {oil }}}{k_{S} D_{S}} T_{S}(x)=-\frac{4 h_{\text {oil }}}{k_{S} D_{S}} T_{\text {oil }}
$$

To solve this differential equation of second order two boundary conditions have to be provided. A similar approach was followed for the other parts constituting the turbocharger model. Two main assumptions were made The first is that the the effective temperature of the gas corresponds to the average temperature at the inlet and the exit to the rotor while the second is that the heat transfer coefficients $\mathrm{n}$ both ends of the shaft is assumed to be equal to those of the turbine $\left(x=L_{S}\right)$ and the compressor $(x=0)$. The final amount of heat delivered by the shaft to the air is then given in Eq. (31).

$$
Q_{S \rightarrow \text { air }}=\frac{1}{4} \pi D_{S}^{2} k_{S}{\frac{d T_{S}}{d x}}_{\mid x=0}
$$

\section{REFERENCES}

[1] Rautenberg M, Mobarak A, Malobabic M, Influence of heat transfer between turbine and compressor on the performance of small turbochargers, Int. Gas Turbine Congress, 1983, IGTC-73.

[2] Rautenberg M, Krammer N, On the thermodynamics of non-adiabatic compression and expansion processes in turbomachines, 1984, Proceedings of the $5^{\text {th }}$ International Conference for Mechanical Power Engineering, Cairo.

[3] Shaaban S, Seume JR, Analysis of turbocharger non-adiabatic performance, 2006, Proceedings of the $8^{\text {th }}$ international conference on turbochargers and Turbocharging, London, C647/027.

[4] Shaaban S, Experimental investigation and extended simulation of turbocharger nonadiabatic performance, PhD Thesis, University of Hannover, 2004.

[5] Hagelstein D, Beyer B, Seume JR, Rautenberg M, Heuristical view on the nonadiabatic coupling system of combustion engine and turbocharger, 2002, Proceedings of the $7^{\text {th }}$ International conference on turbochargers and turbocharging, London, C602/015. 
[6] Jung M, Ford R, Glover K, Collings N, Christen U, Watts M, Parameterization and transient validation of a variable geometry turbocharger for mean-value modeling at low and medium speed-load points, SAE Powertrain and fluid systems conference, San Diego, 2002, SAE 2002-01-2729.

[7] Cormerais M, Hetet JF, Chesse P, Maiboom A, Heat transfer analysis in a turbocharger compressor: Modeling and experiments, SAE world congress, Detroit, 2006, SAE 2006-01-0023.

[8] Abdelhamid S, Berndt R, Grigoriadis P, Hagelstein D, Nickel J, Pucher H, Seume JR, Advanced presentation and extrapolation of turbocharger maps as a boundary condition of the engine process simulation, 2003, Stuttgart international symposium on motor vehicles and engines, Stuttgart.

[9] Chapman KS, Nguru R, Shultz J, Simplified methodology to correct turbocharger field measurements for heat transfer and other effects, Final Report for gas research institute, 2002, GRI-02/0156.

[10] Bohn D, Heuer T, Kusterer K, Conjugate flow and heat transfer investigation of a turbocharger: Part i - numerical results, Proceedings of ASME turbo expo, Atlanta, 2003, GT2003-38445.

[11] Bohn D, Moritz N, Wolff M, Conjugate flow and heat transfer investigation of a turbo charger: Part ii - experimental results, Proceedings of ASME turbo expo, Atlanta, 2003, GT-2003-38849.

[12] Heuer T, Engels B, Wollscheid P, Thermomechanical analysis of a turbocharger based on conjugate heat transfer, Proceedings of ASME turbo expo, Reno-Tahoe (Nevada), 2005, GT 2005-68059.

[13] Baines N, Wygant KD, Antonis D, The analysis of heat transfer in automotive turbochargers, Proceedings of the ASME turbo expo, Orlando, 2009, GT2009-59353.

[14] Casey MV, Schlegel M, Performance estimation of turbocharger compressor at low pressure ratios, Institute of thermal turbomachinery (ITSM), University of Stuttgart, 2008.

[15] Casey MV, Fesich TM, On the efficiency of compressors with adiabatic flows, Proceedings of the ASME turbo expo, Orlando, 2009, GT 2009-59015.

[16] Stanitz JD, Some theoretical aerodynamic investigations of impellers in radial and mixed flow centrifugal compressors, Proceedings of the ASME turbo expo, 1952, pp. 74- 473. 
[17] Rodgers C, A diffusion factor correlation for centrifugal impeller stalling, Proceedings of the ASME turbo expo, 1978, GT-61.

[18] Koonlaya K, Heat transfer investigation of jet impingement coupled with dimples, PhD Thesis, Imperial College London, 2004.

[19] Cengel YA, Heat Transfer: A Practical Approach, McGraw-Hill (Tx); $2^{\text {nd }}$ edition, 2002.

[20] Dittus PW, Boelter LMK, Heat Transfer in Automobile Radiators of the Tubular Type. University of California Publication Engineer, Vol. 2, pp. 232- 248, 1930.

[21] Lewandoski W, Radziemska E, Heat Transfer by Free Convection from an Isothermal Vertical Round Space in Unlimited Space. Applied Energy, Vol. 68, pp. 187-201, 2001.

[22] Lomas CG, Fundamentals of hot-wire anemometry. Cambridge University Press, pp. 63-69, 1986.

[22] Bayley F J, Owen JM, Turner AB, Heat Transfer. William Clowes and Sons Ltd., London, 1972.

[23] Kumm B, Development and Application of a Theoretical Model to Predict Heat Fluxes from the Turbine to the Compressor in a Turbocharger. Final year project report, Imperial College of Science, Technology, and Medicine - University of London, UK, 2007. 


\section{FIGURES}

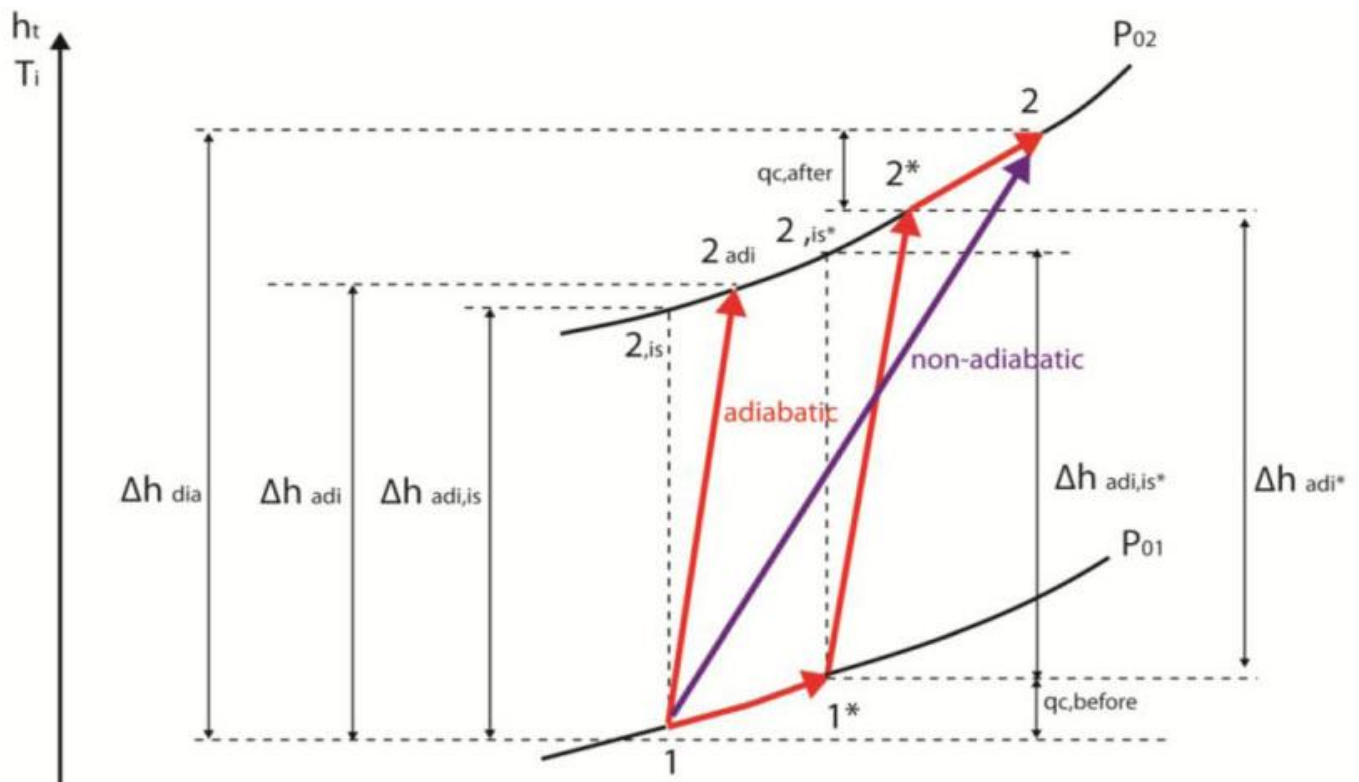

Figure 1: Compression diagram 


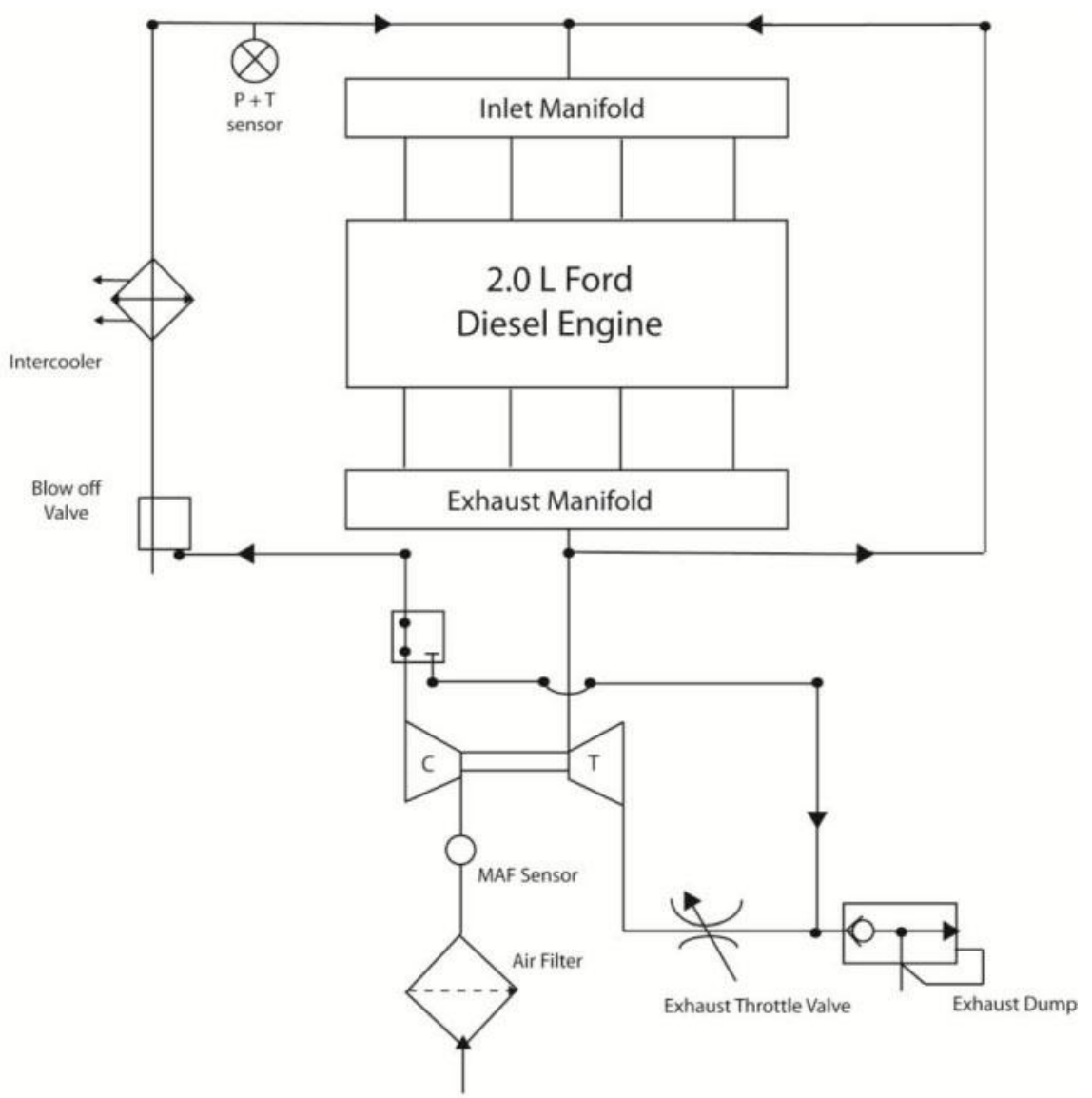

Figure 2: Test rig layout (Kyartos 2006)

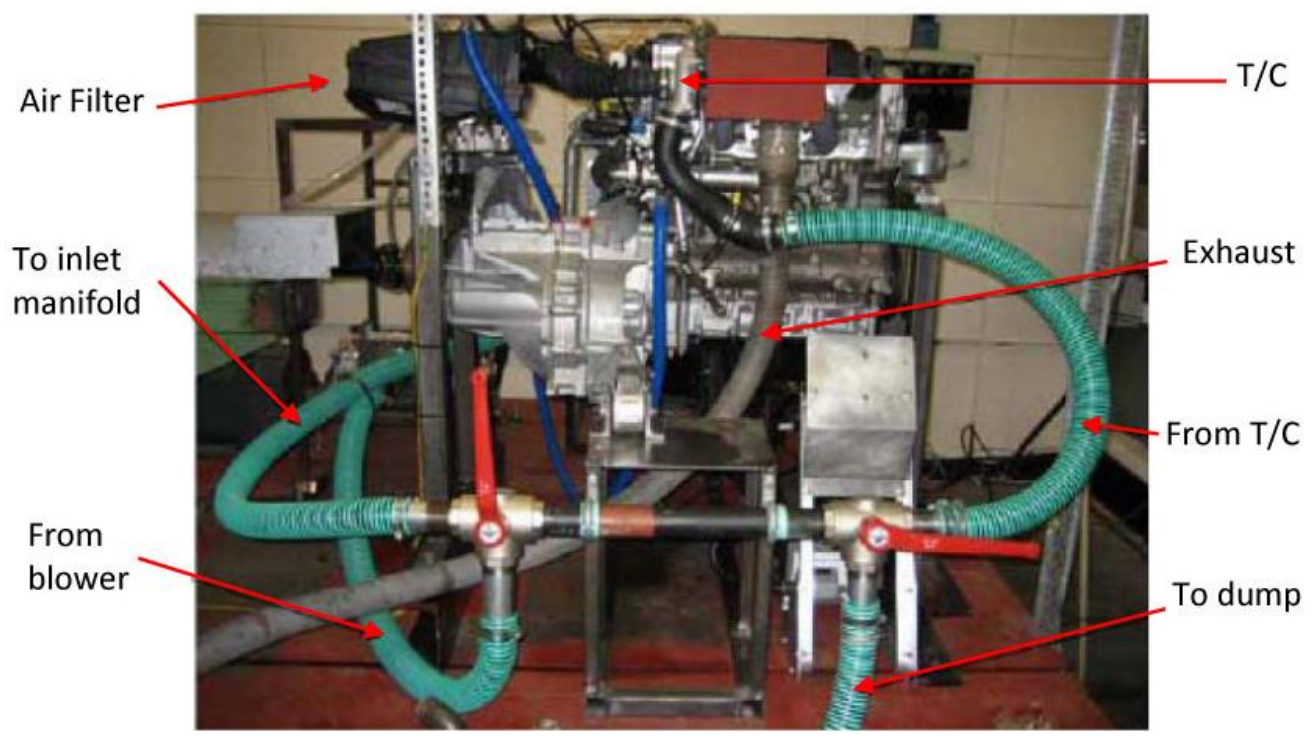

Figure 3: Test rig overview (Kyartos 2006) 
A-Compressor layout

B- Turbine layout

C- Exhaust manifold surface thermocouples

D- Bearing housing thermocouples

E- Oil flow sensor

F- Oil temperature thermocouples

G- Speed sensor

$\mathrm{H}$ - Top view instrumented turbocharger
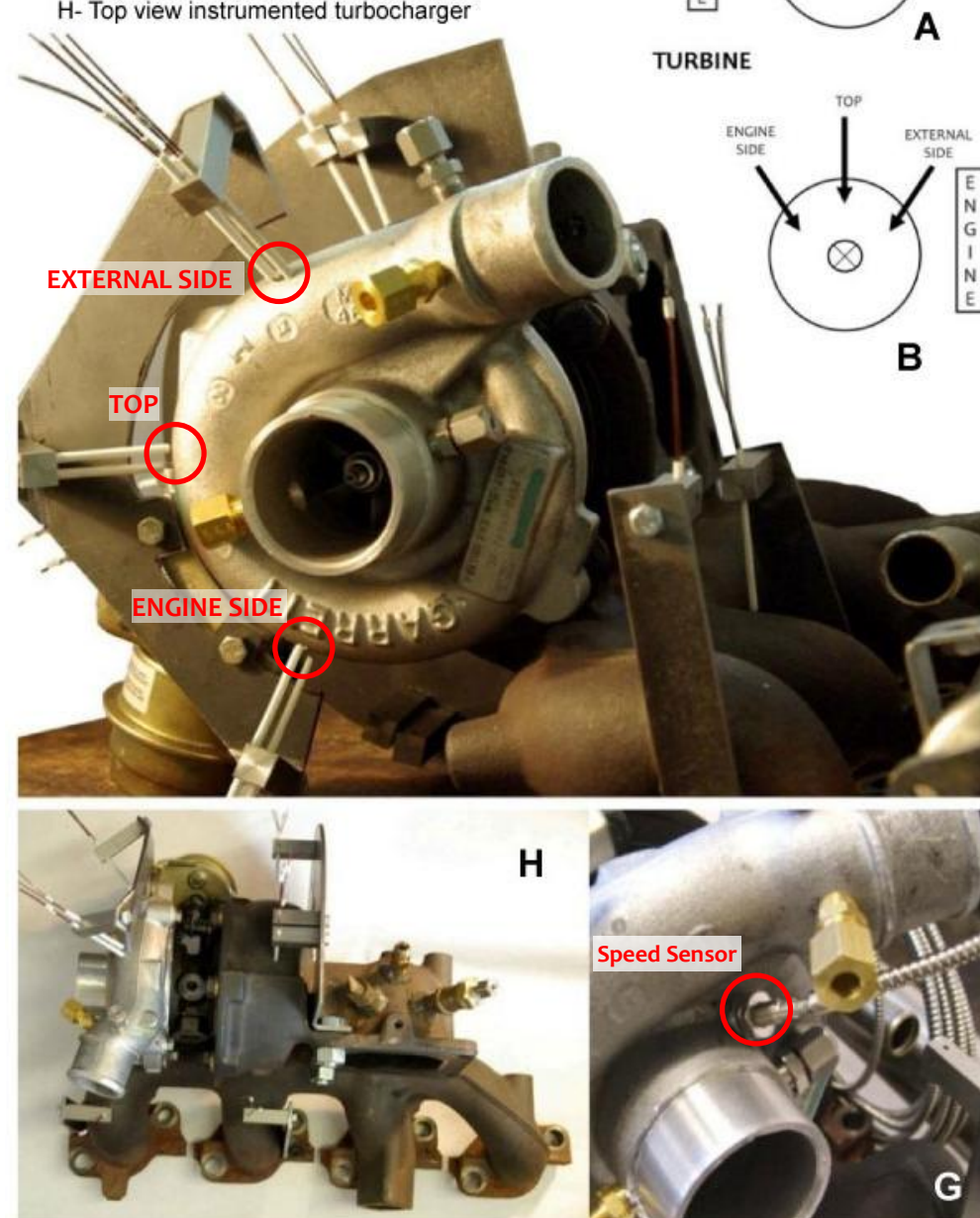

COMPRESSOR
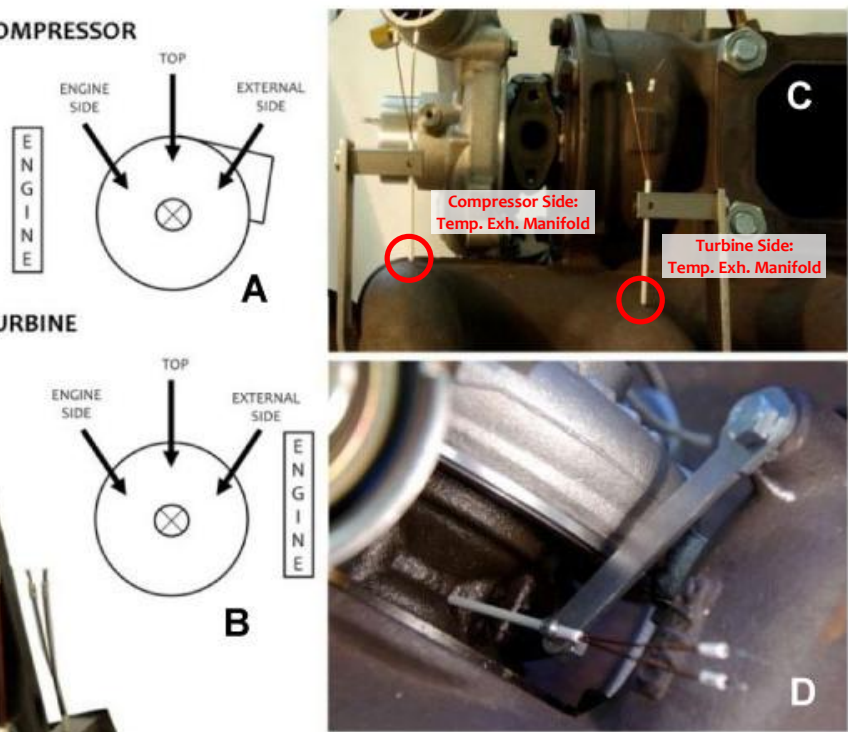

D
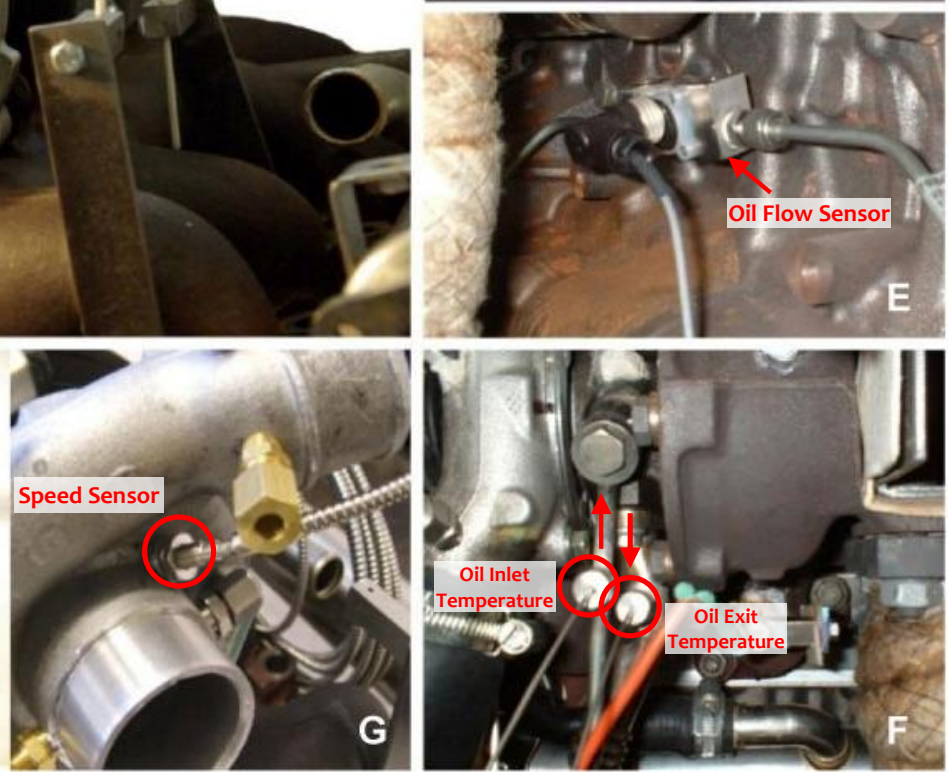

Figure 4: Instrumented turbocharger 


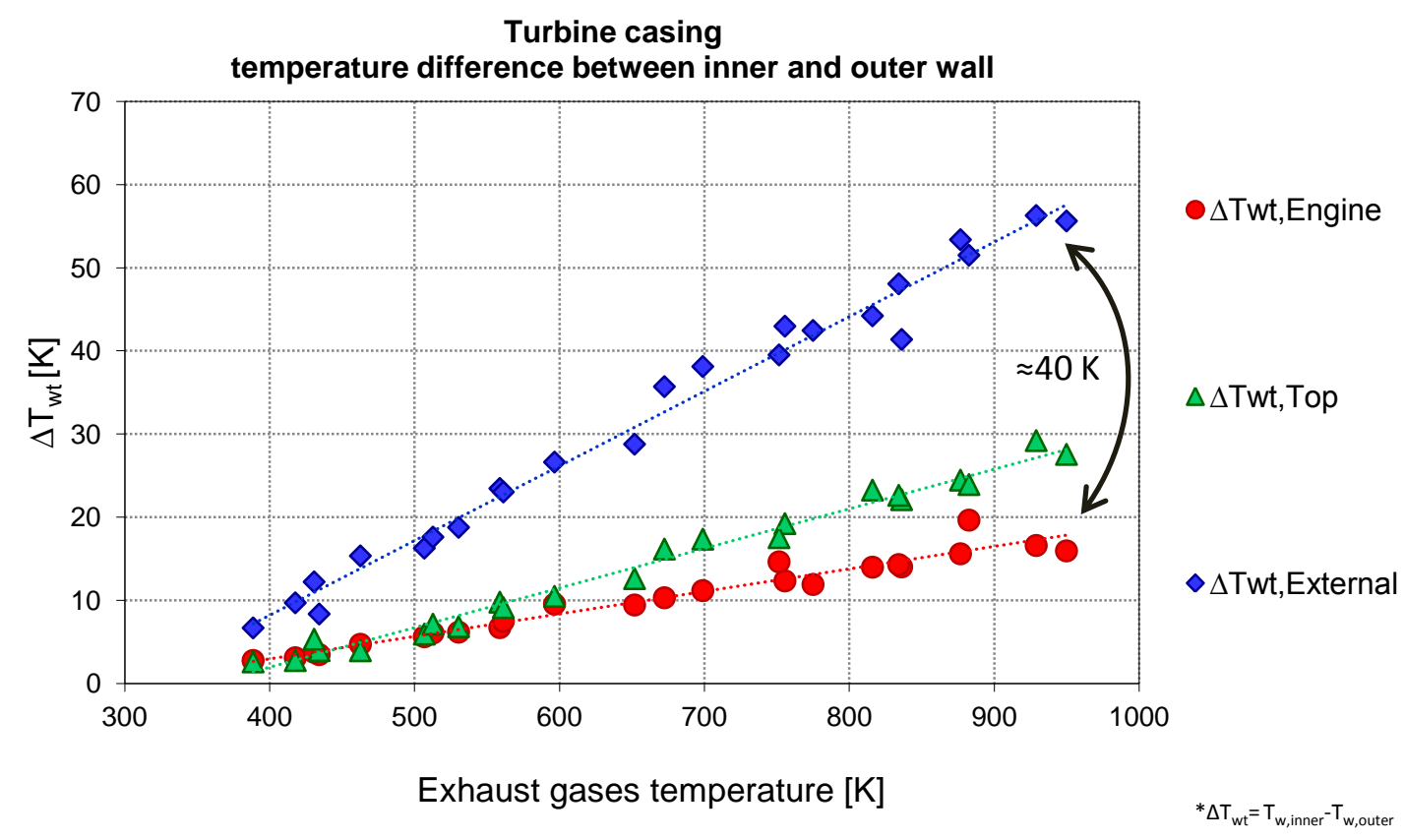

Figure 5: Turbine casing: inner - outer wall temperature difference in the three locations

Engine, Top and External side

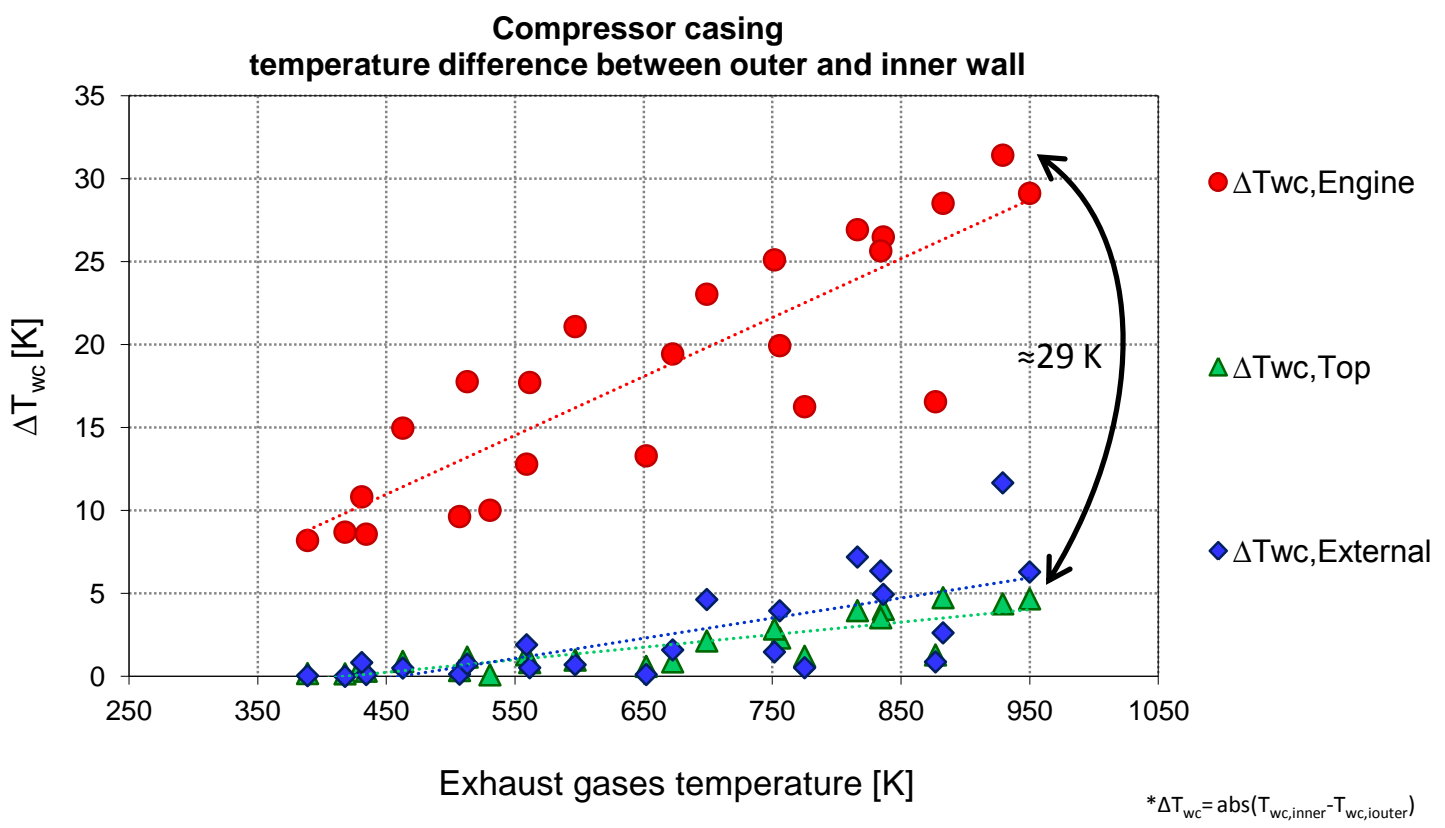

Figure 6: Compressor casing: outer - inner wall temperature difference in the three locations

Engine, Top and External side 


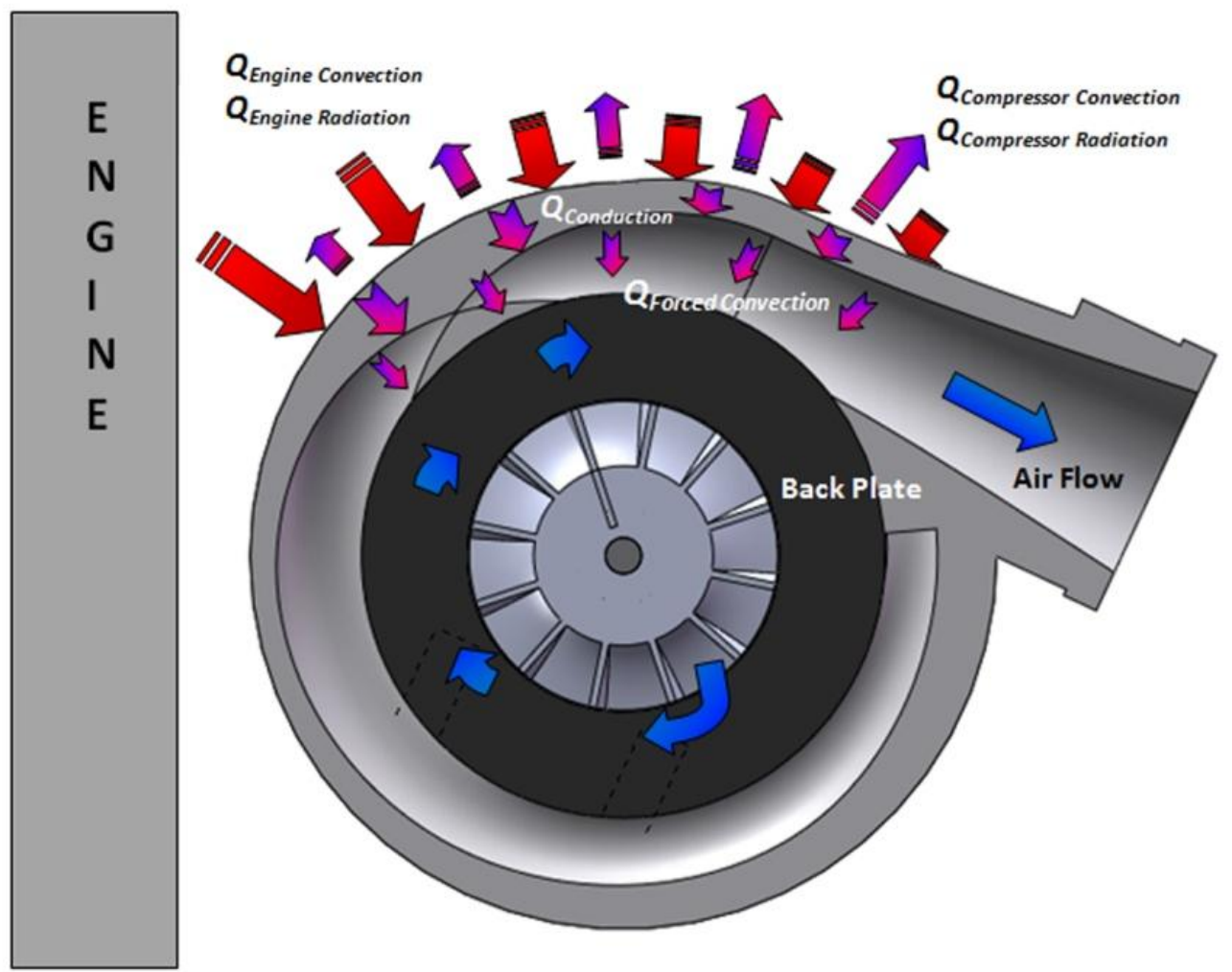

Figure 7: Compressor casing: occurring heat fluxes

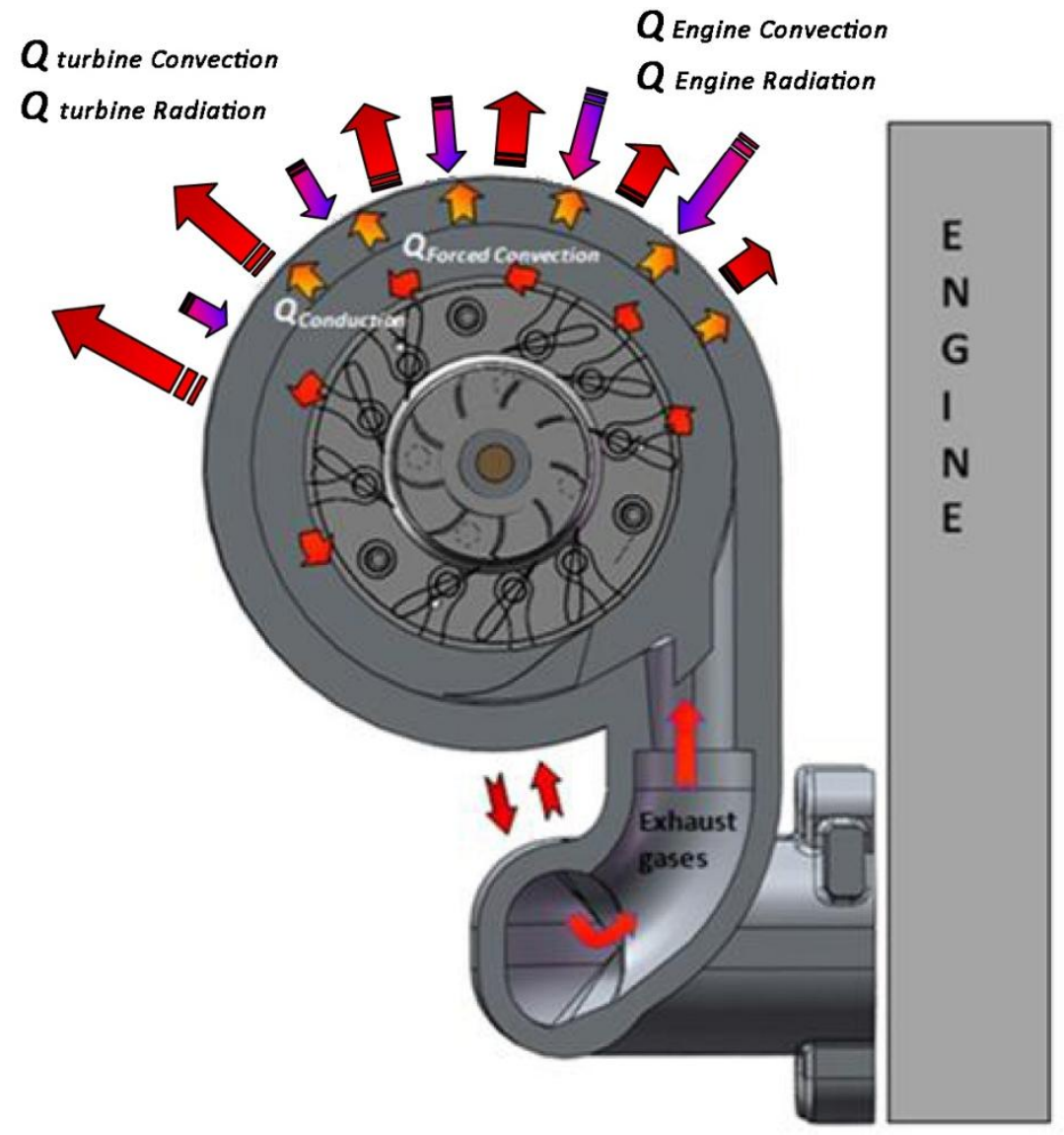

Figure 8: Turbine casing: occurring heat fluxes 


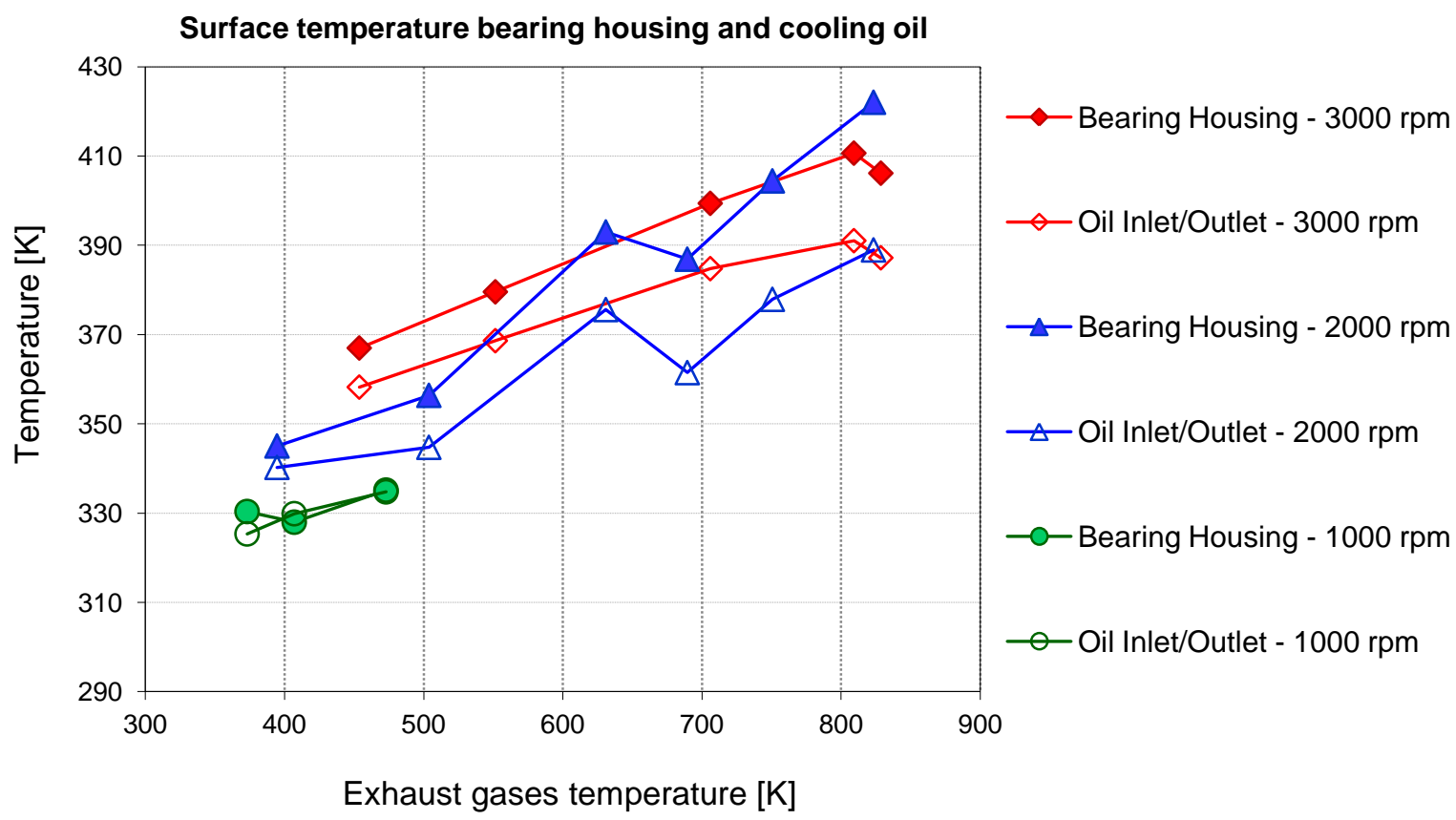

Figure 9: Temperature trend for the cooling oil and the bearing housing

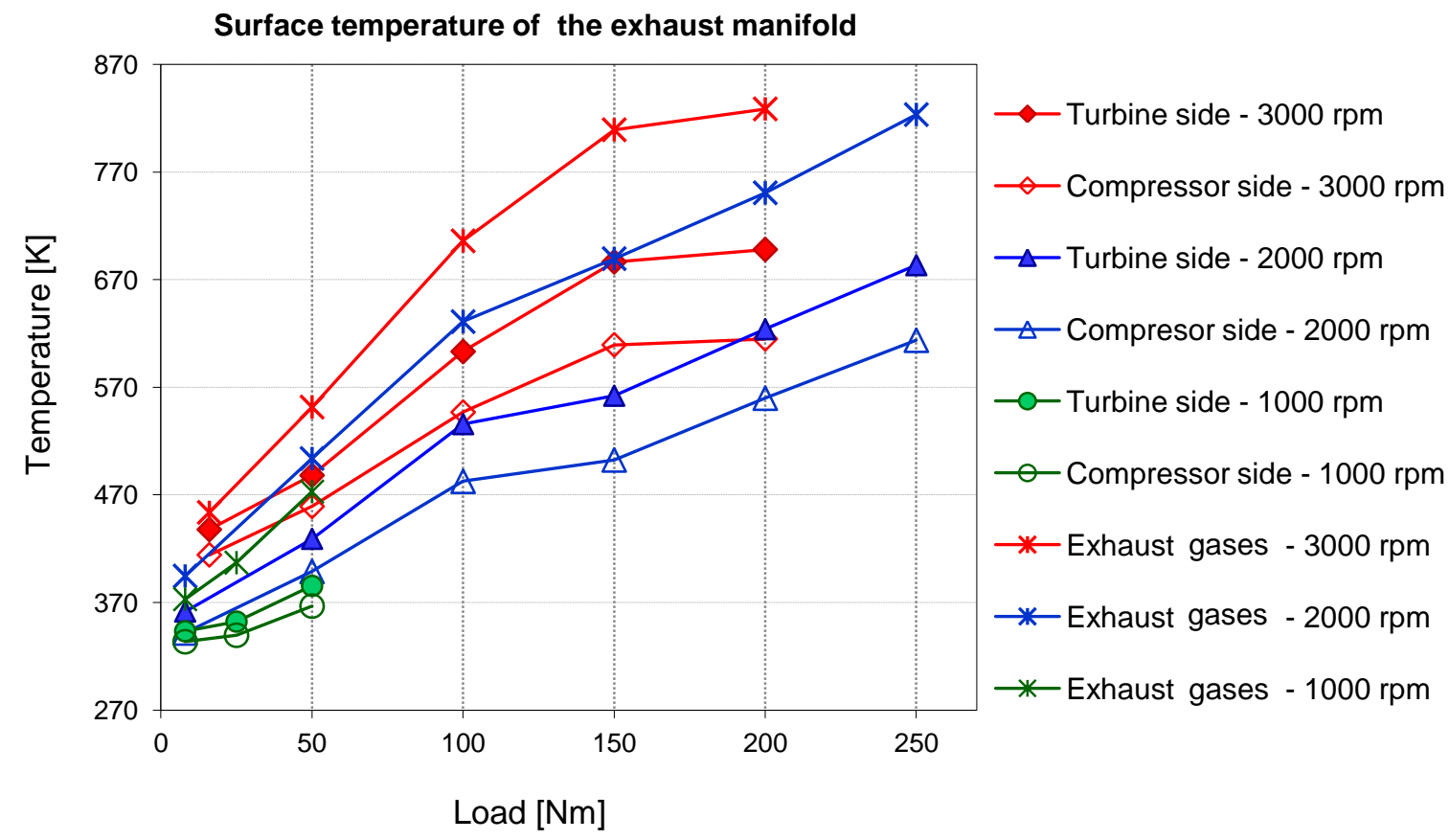

Figure 10: Temperature trend for the exhaust manifold and exhaust gases 


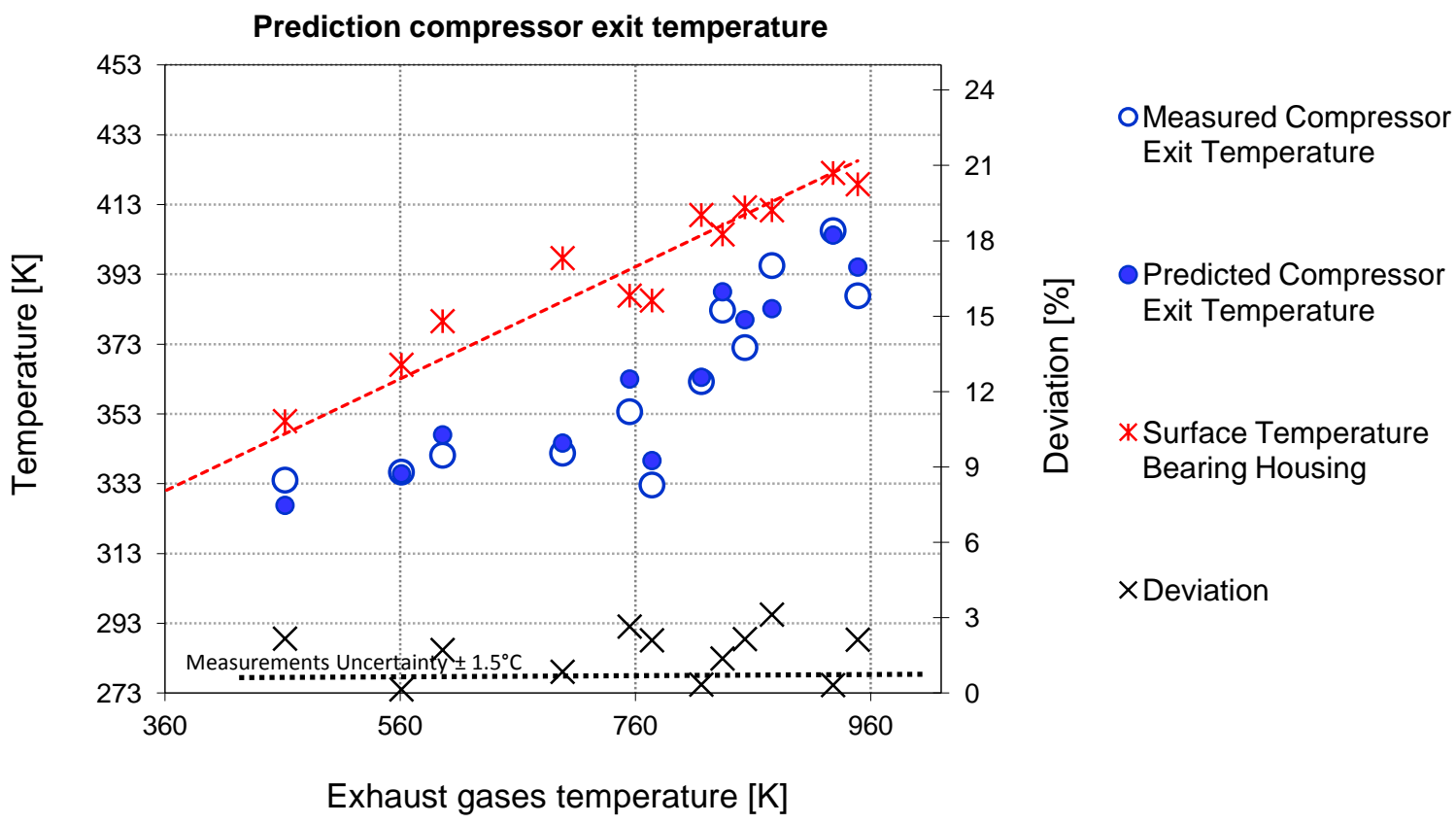

Figure 11: Compressor exit temperature

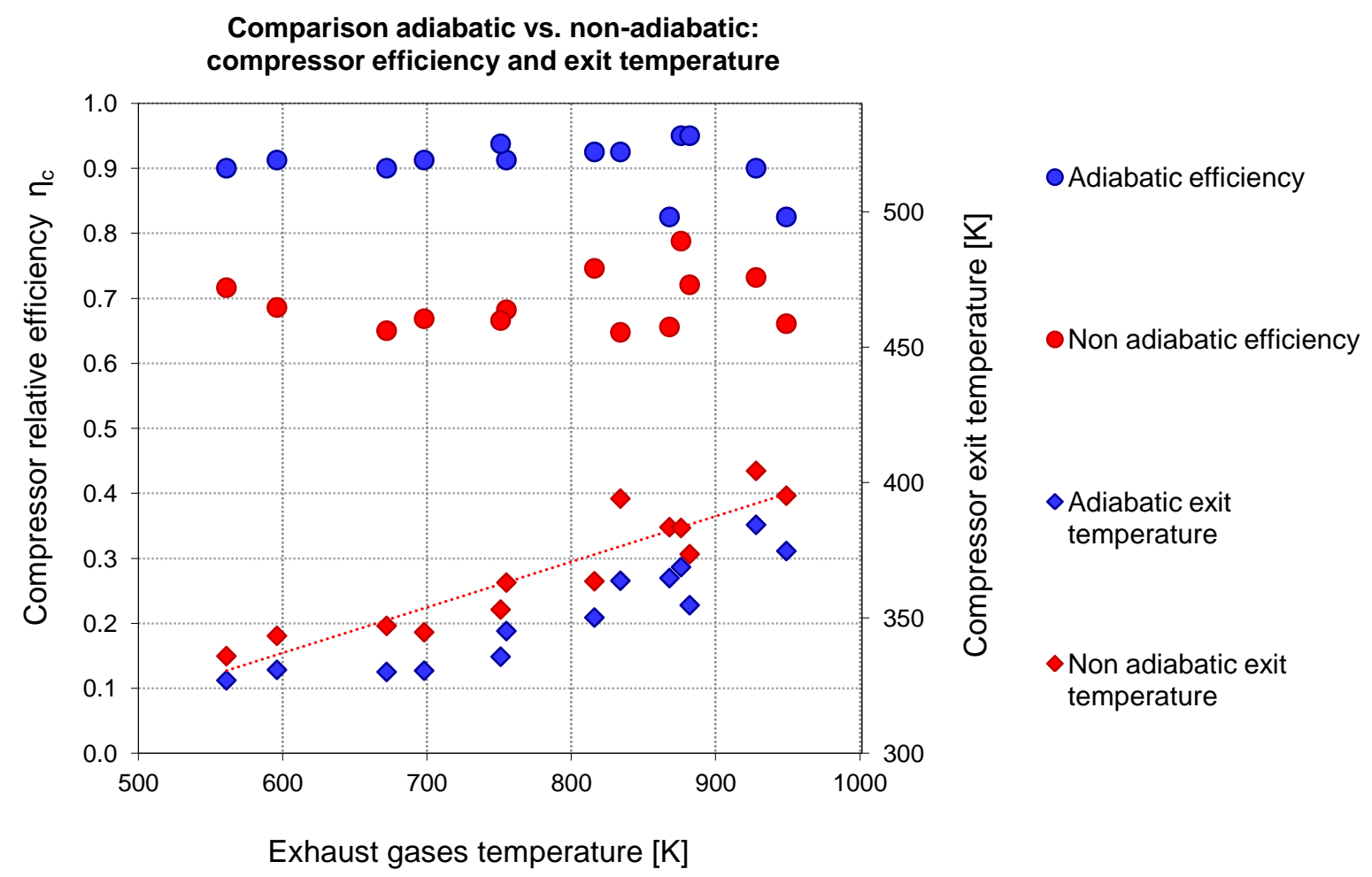

Figure 12: Adiabatic vs. non-adiabatic compressor efficiency and exit temperature 

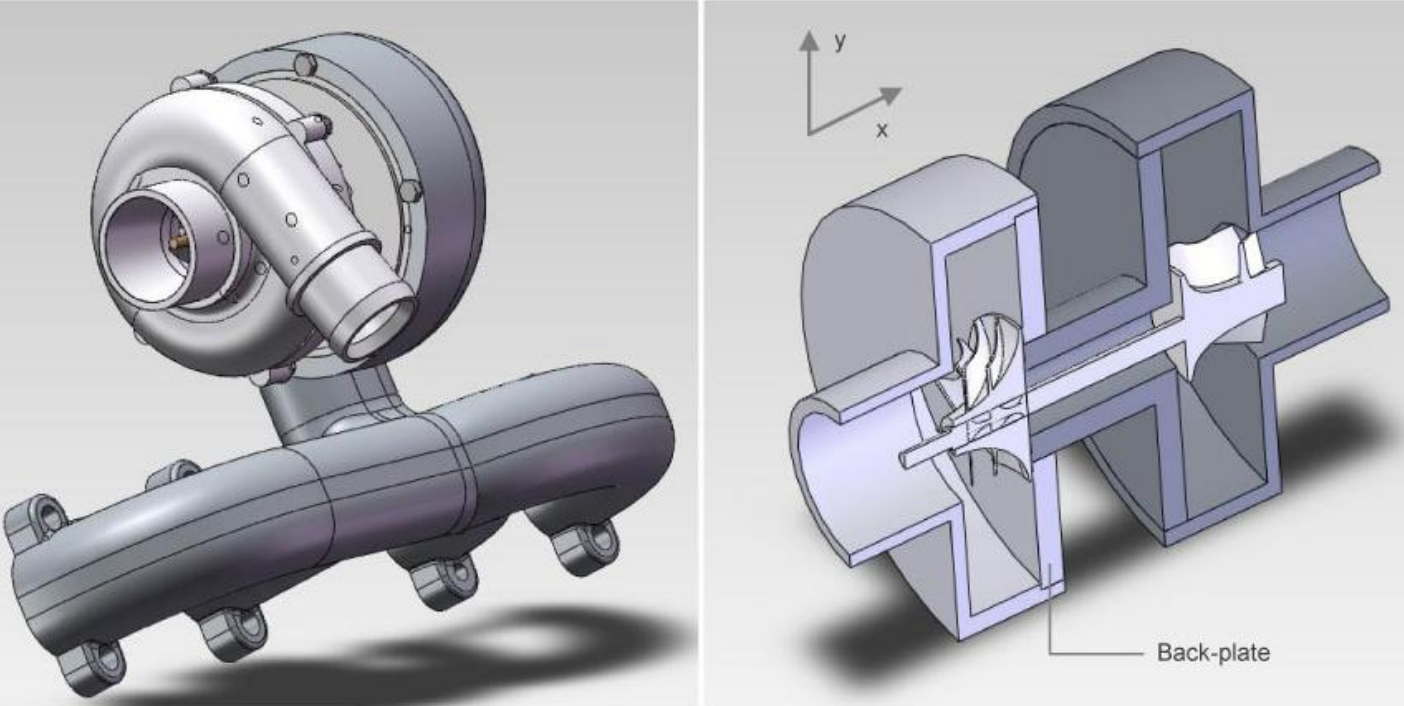

Figure 13: Physical Model - A: Real model of the turbocharger - B: Simplified geometry included in the 1-D model

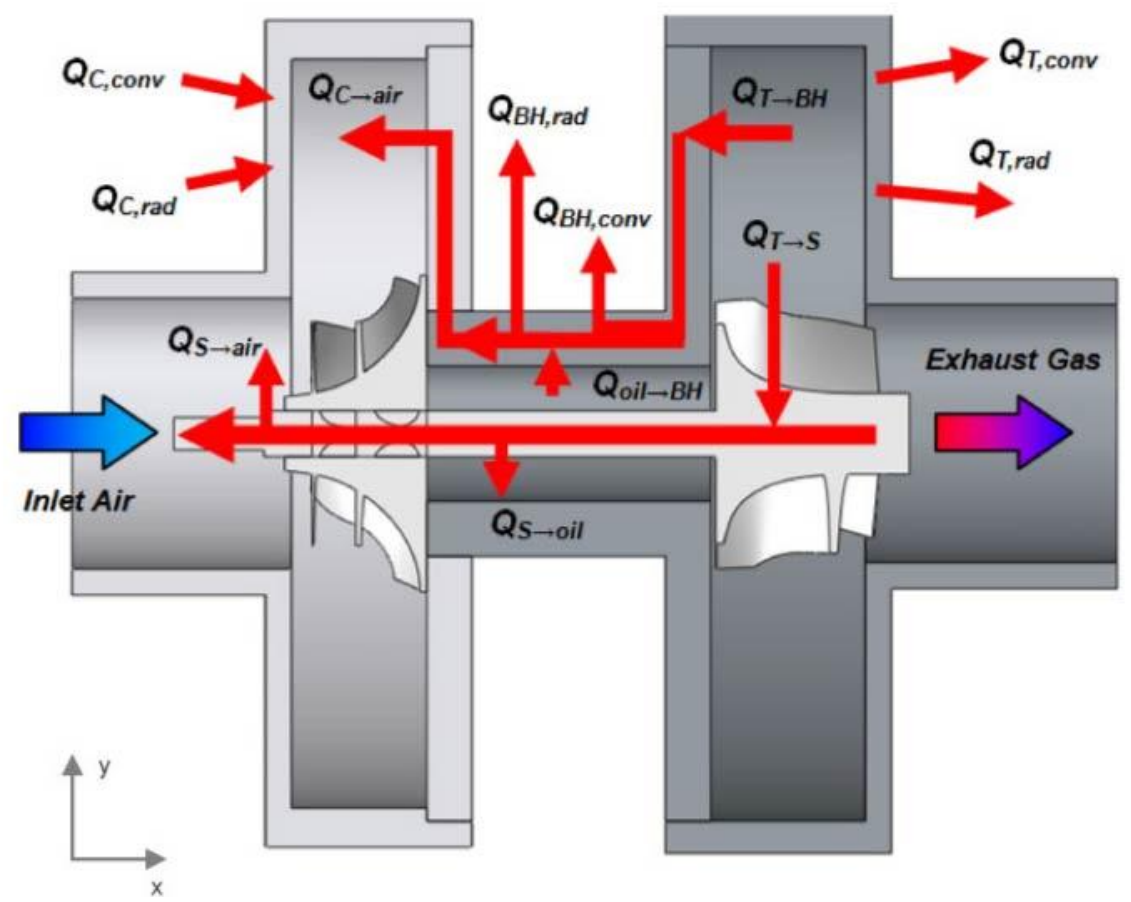

Figure 14: Reduced order heat transfer model 


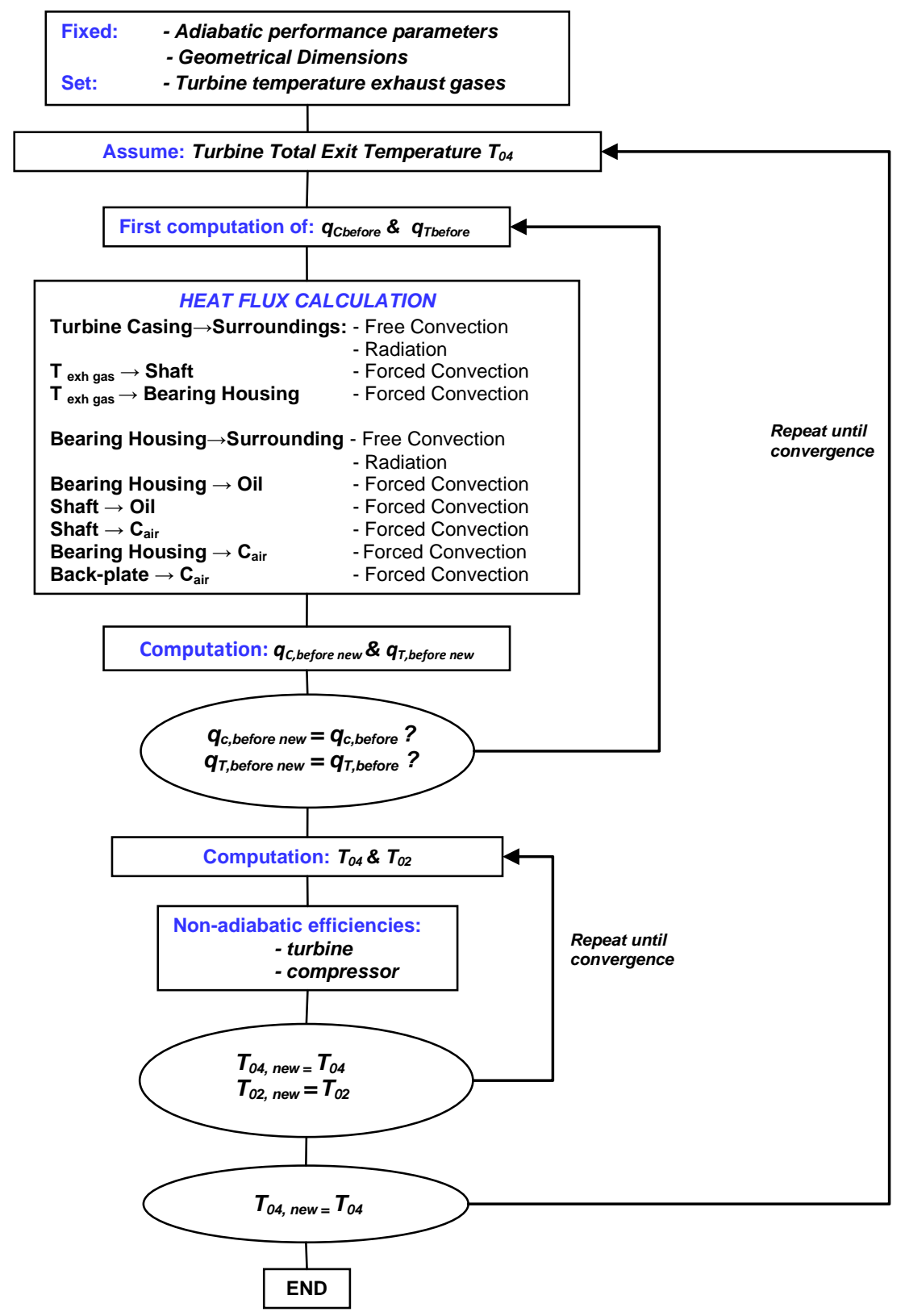

Figure 15: Model flow chart 


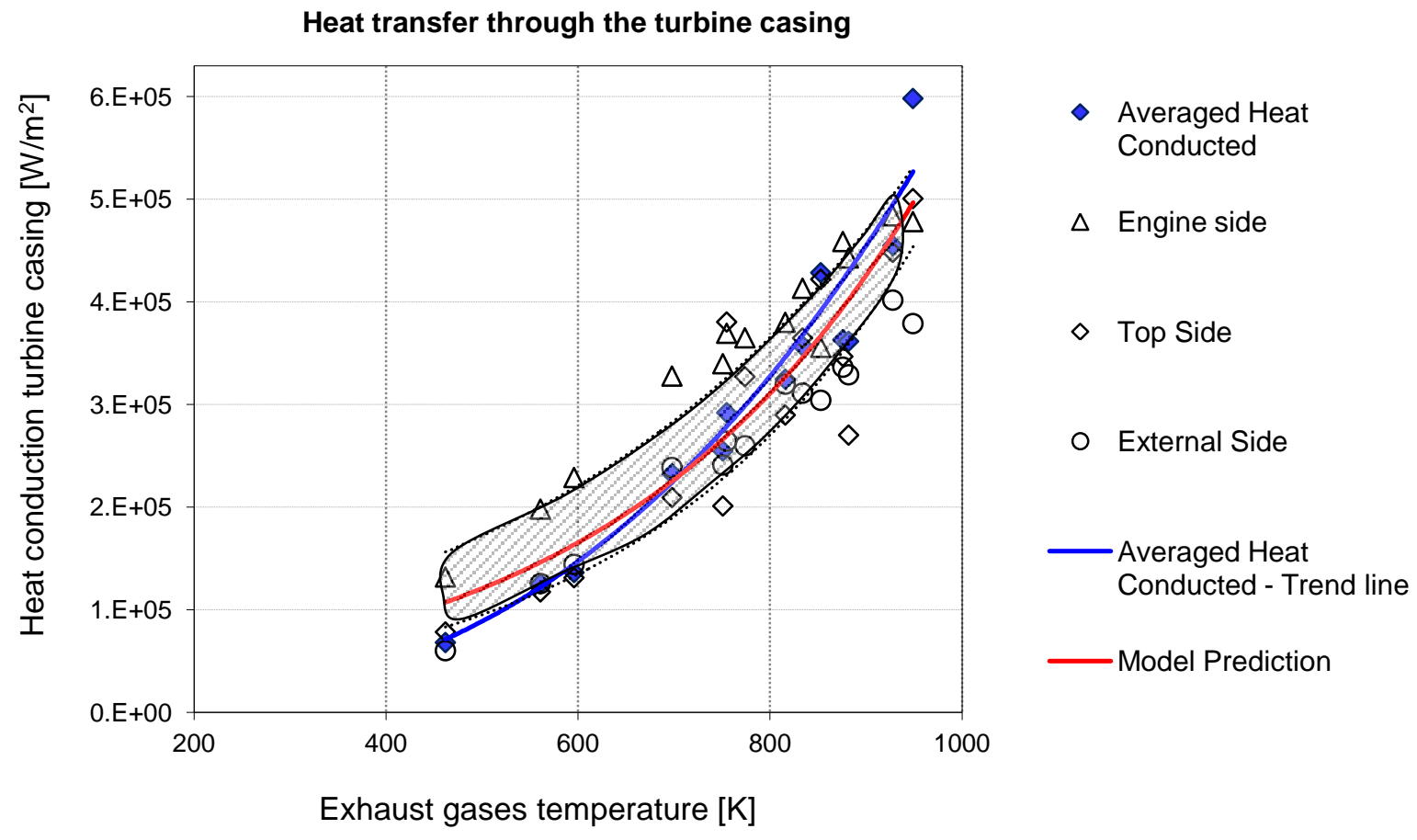

Figure 16: Heat conducted through the turbine casing

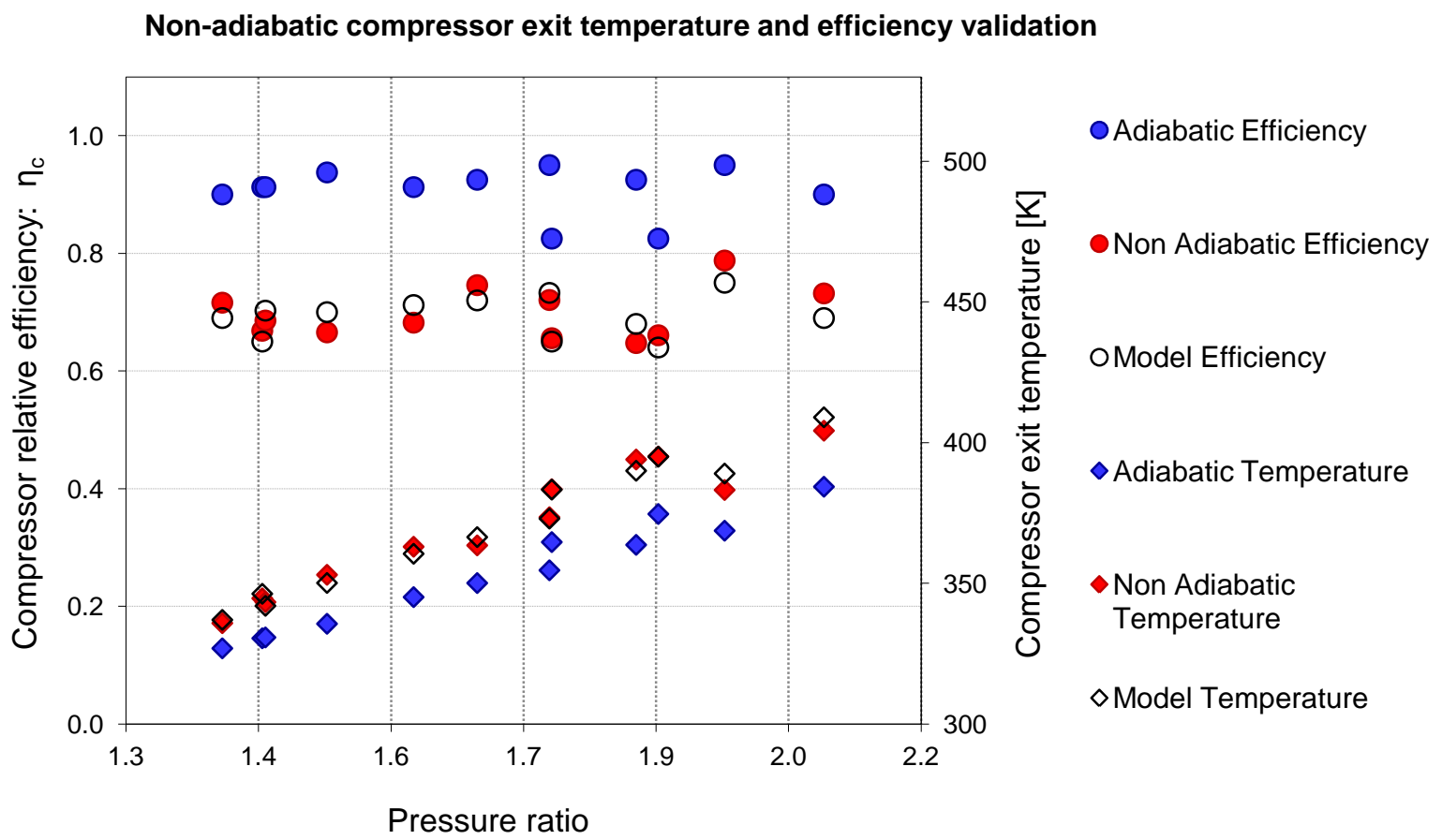

Figure 17: Model validation: exit temperature and compressor non-adiabatic efficiency 


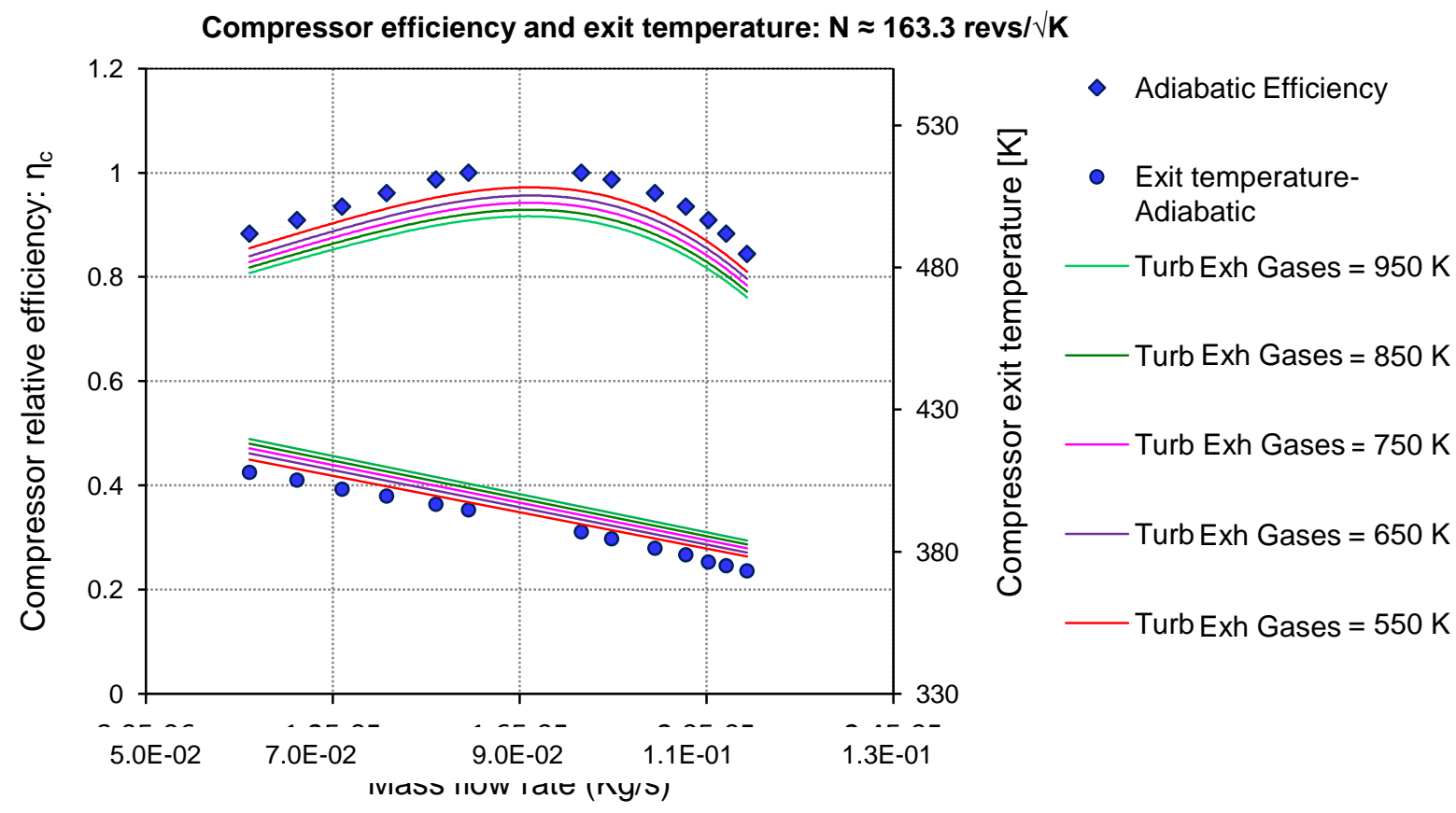

Figure 18: Compressor relative non-adiabatic efficiency vs. mass flow rate for different temperatures of the exhaust gases $(950 \mathrm{~K}, 850 \mathrm{~K}, 750 \mathrm{~K}, 650 \mathrm{~K}$ and $550 \mathrm{~K})$ at $163.3 \mathrm{revs} / \sqrt{\mathrm{K}}$

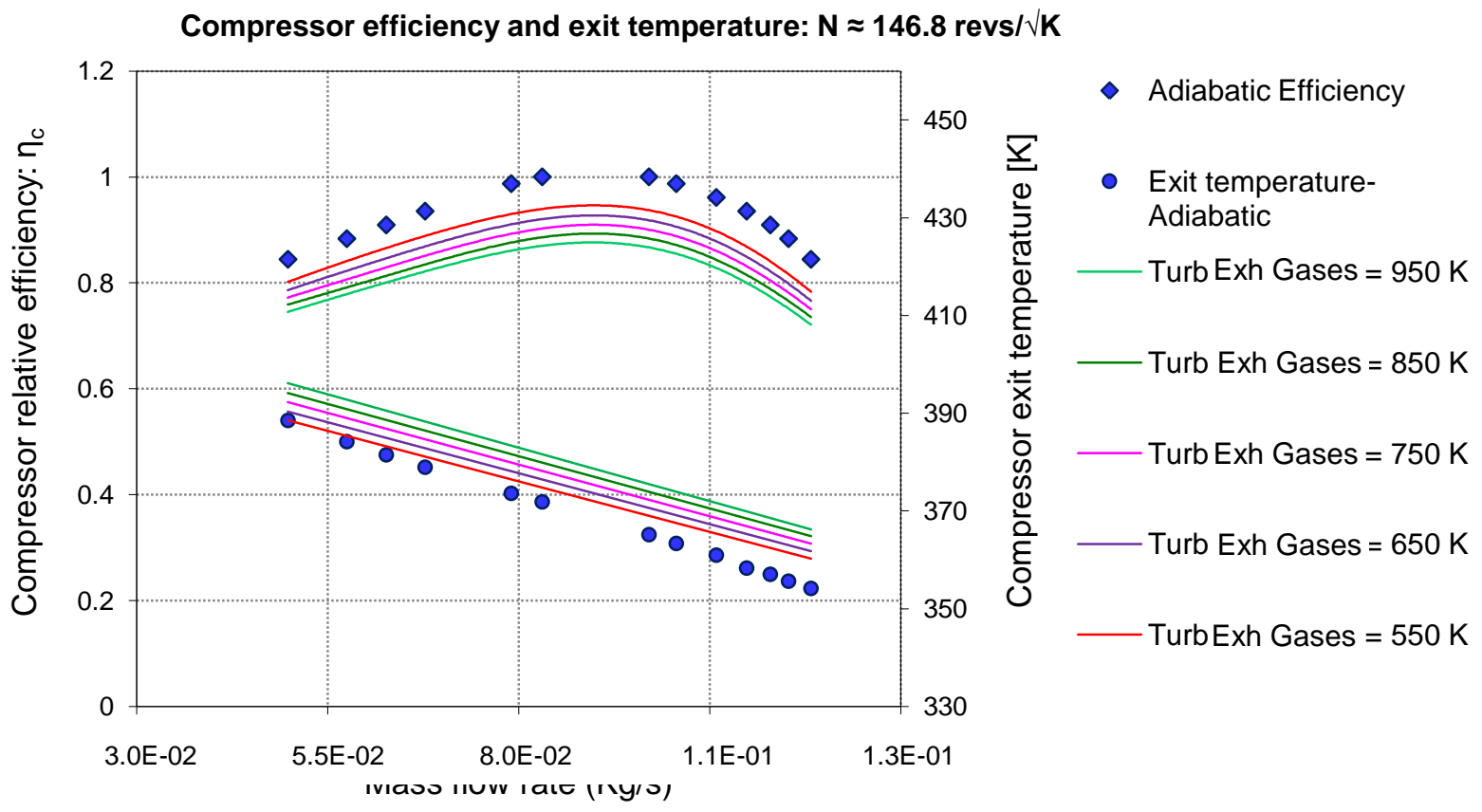

Figure 19: Compressor relative non-adiabatic efficiency vs. mass flow rate for different temperatures of the exhaust gases $(950 \mathrm{~K}, 850 \mathrm{~K}, 750 \mathrm{~K}, 650 \mathrm{~K}$ and $550 \mathrm{~K})$ at $146.8 \mathrm{revs} / \sqrt{\mathrm{K}}$ 


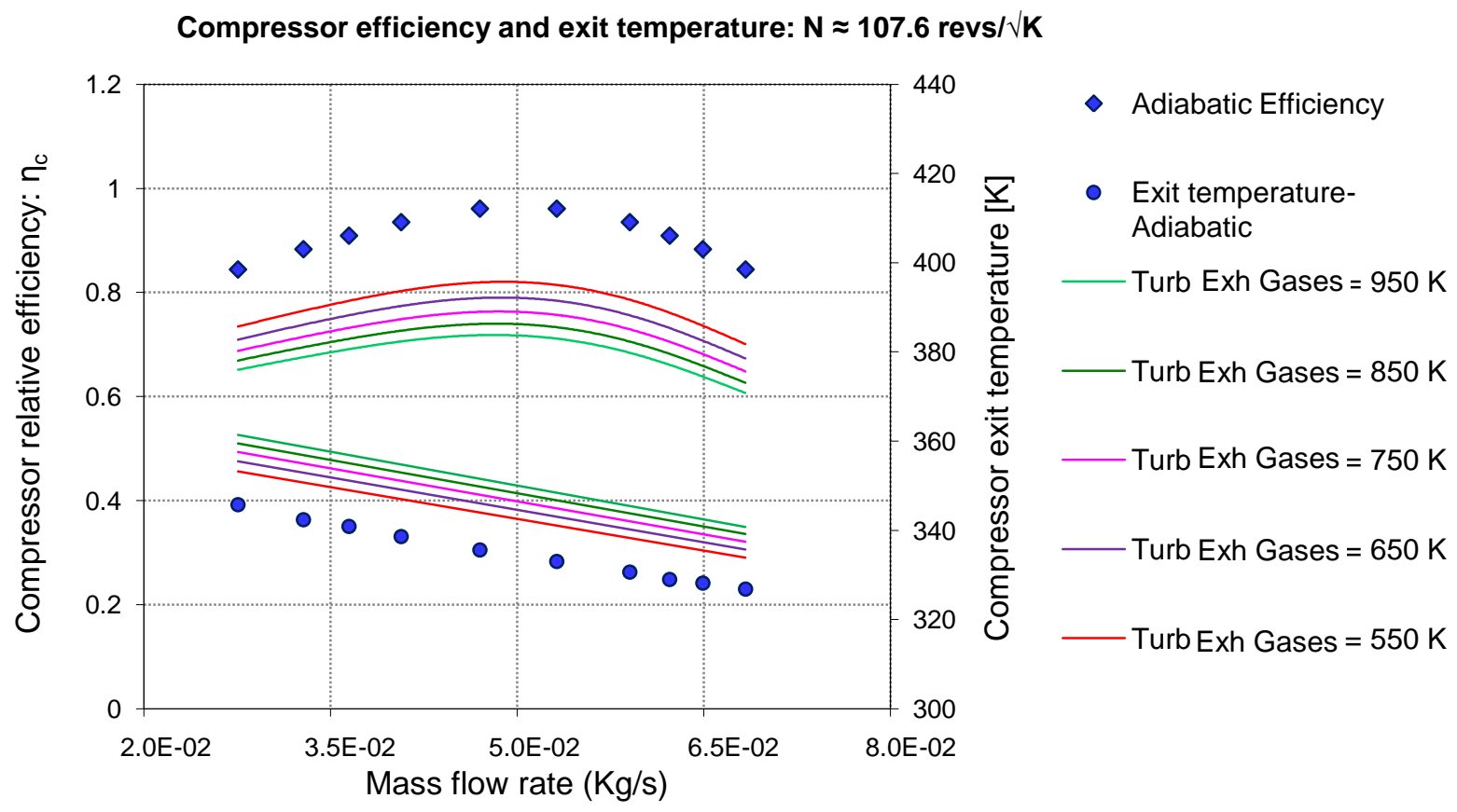

Figure 20: Compressor relative non-adiabatic efficiency vs. mass flow rate for different temperatures of the exhaust gases $(950 \mathrm{~K}, 850 \mathrm{~K}, 750 \mathrm{~K}, 650 \mathrm{~K}$ and $550 \mathrm{~K})$ at $107.6 \mathrm{revs} / \sqrt{\mathrm{K}}$

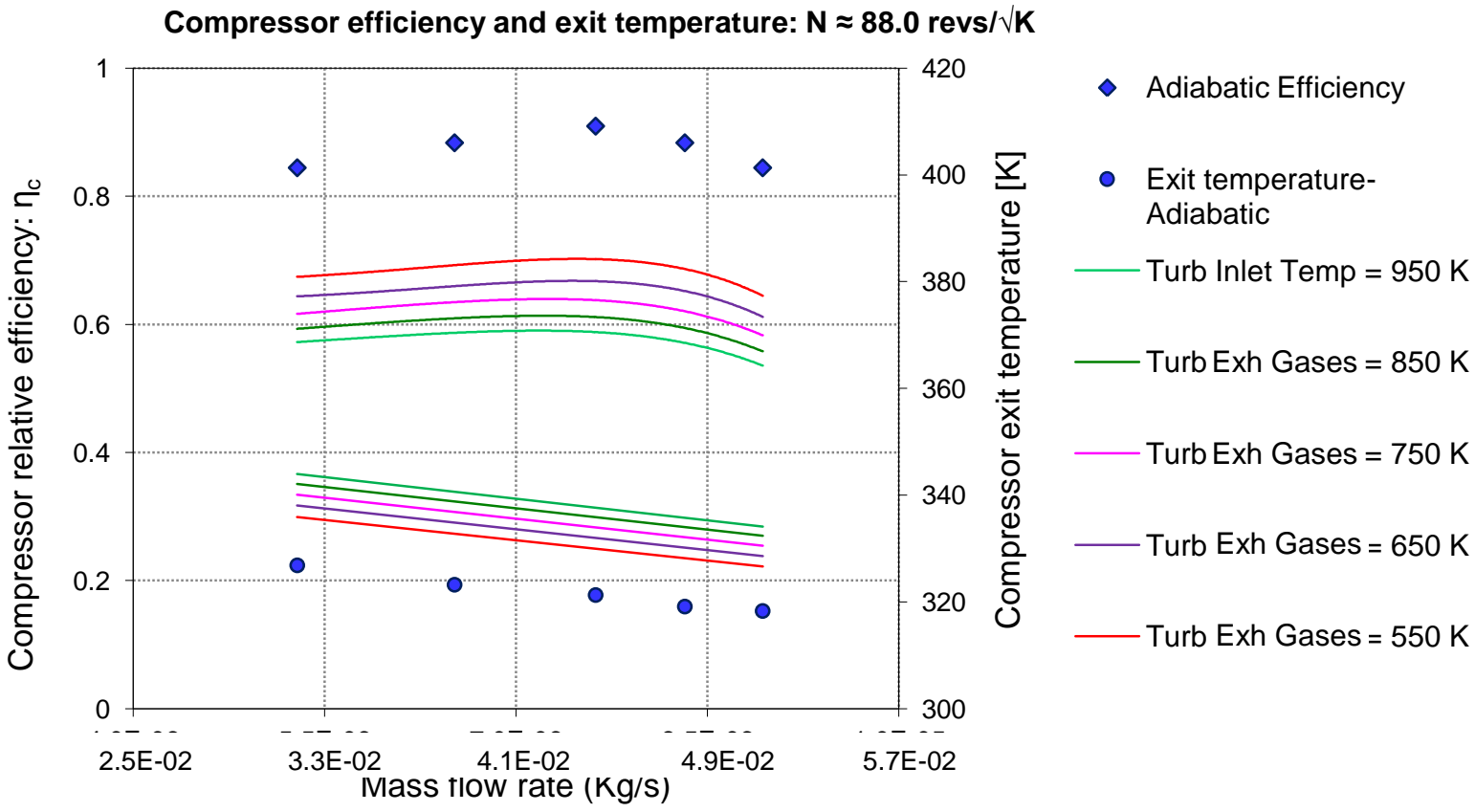

Figure 21: Compressor relative non-adiabatic efficiency vs. mass flow rate for different temperatures of the exhaust gases $(950 \mathrm{~K}, 850 \mathrm{~K}, 750 \mathrm{~K}, 650 \mathrm{~K}$ and $550 \mathrm{~K})$ at $88.0 \mathrm{revs} /_{\textrm{K}}$ 

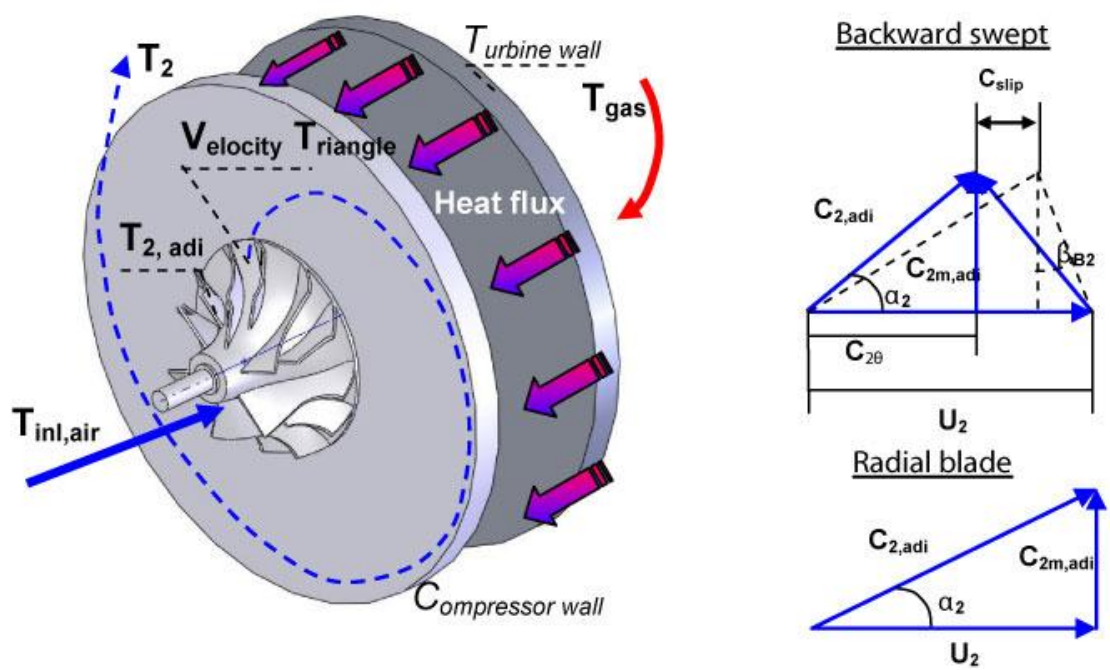

Figure 22: Heat transfer process within the turbocharger and exit velocity triangles

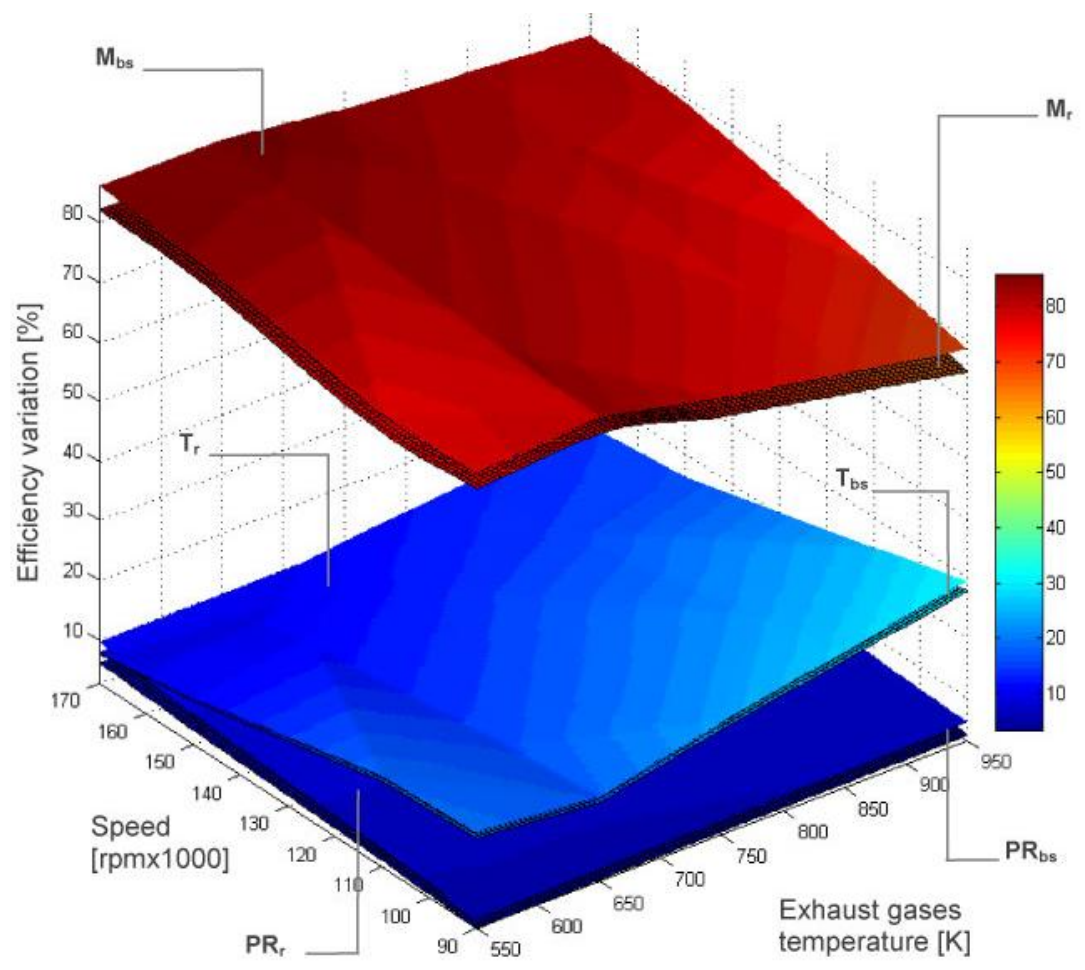

Figure 23: Contribution of $M, P R$, and $T P$ to the compressor performance, 3-D diagram 


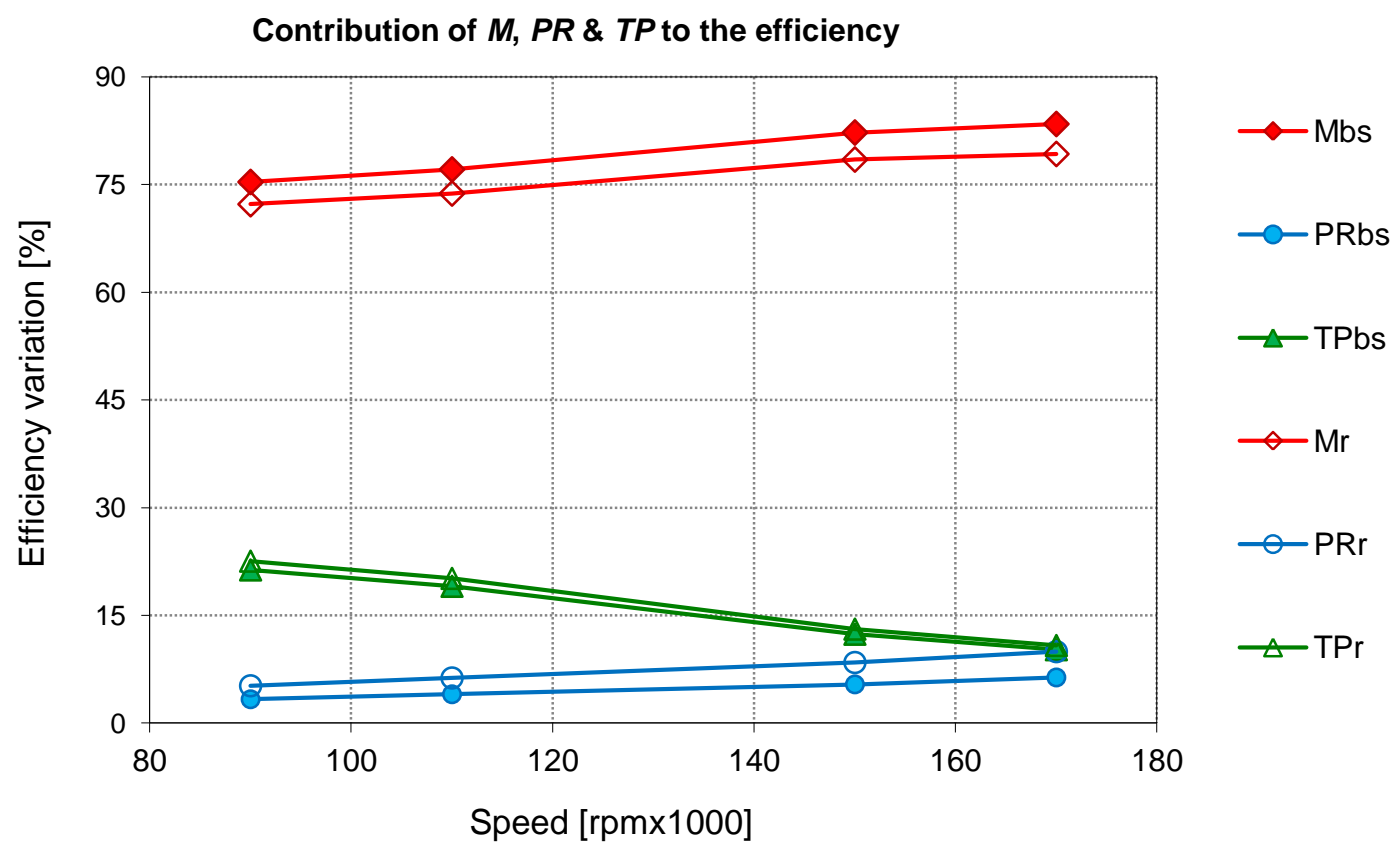

Figure 24: Contribution of $M, P R$, and $T P$ to the compressor performance, 2-D plot with averaged values of the variables

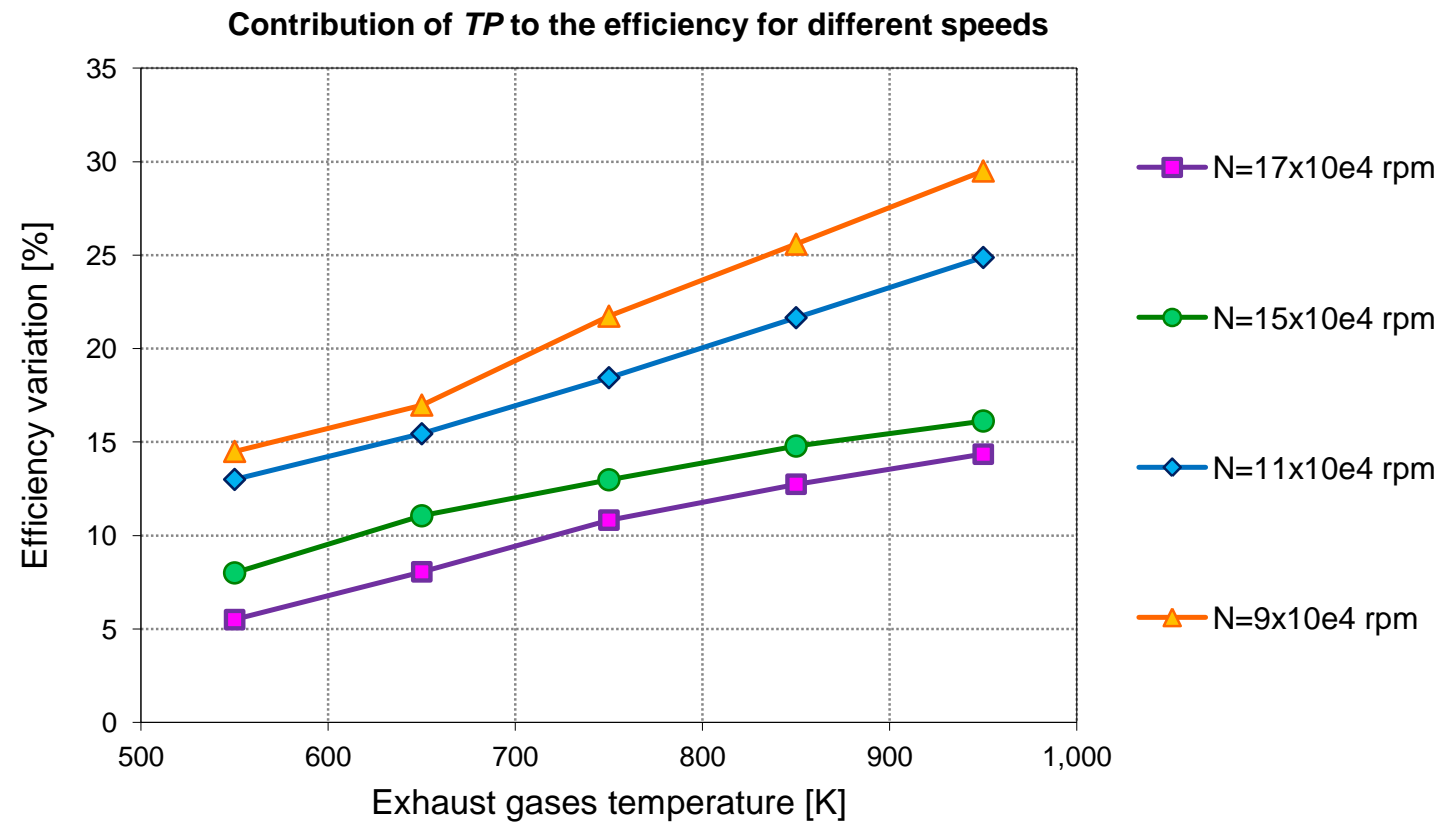

Figure 25: Contribution of $T P$ to the compressor performance: $T P$ vs. temperature for constant speed lines 


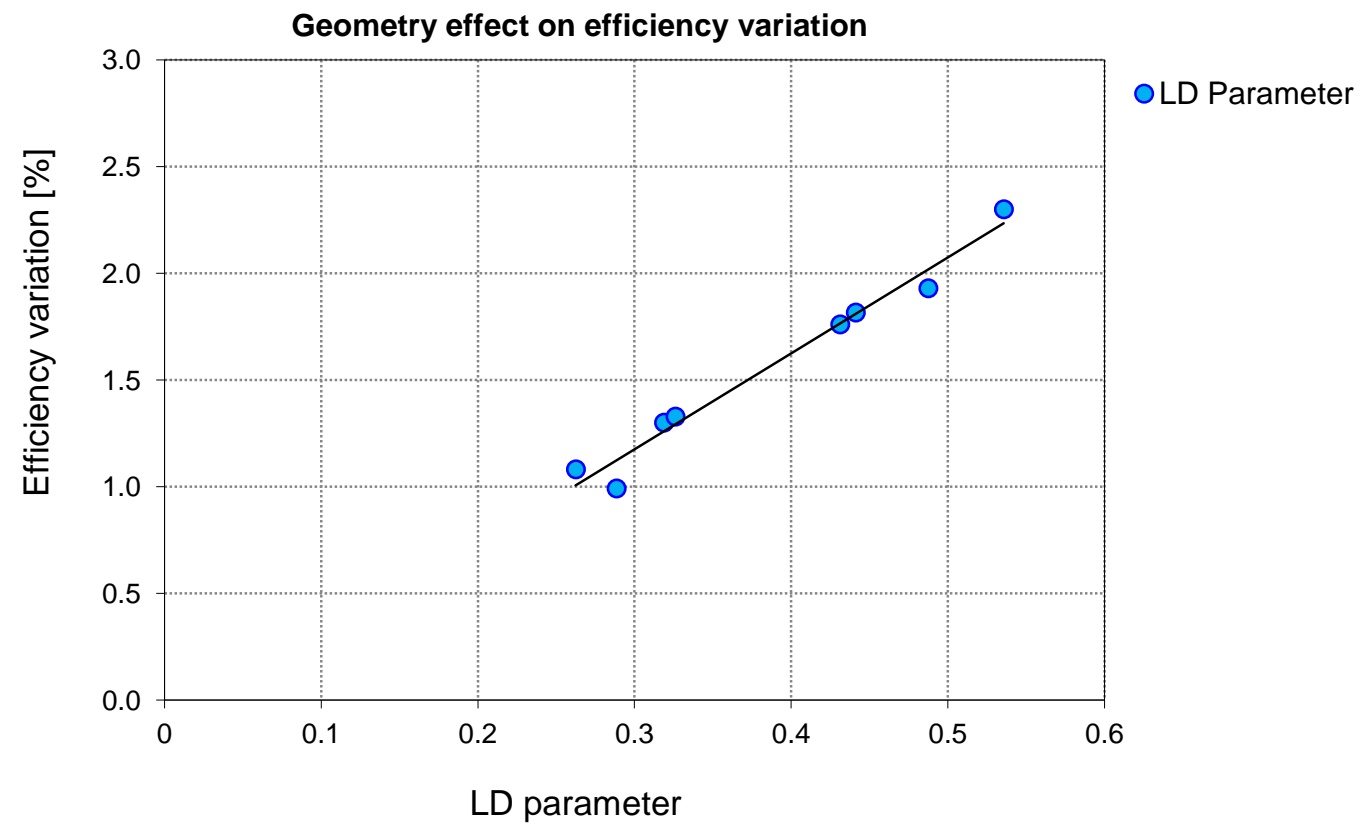

Fig. 26: $L D$ contribution to the compressor non-adiabatic efficiency

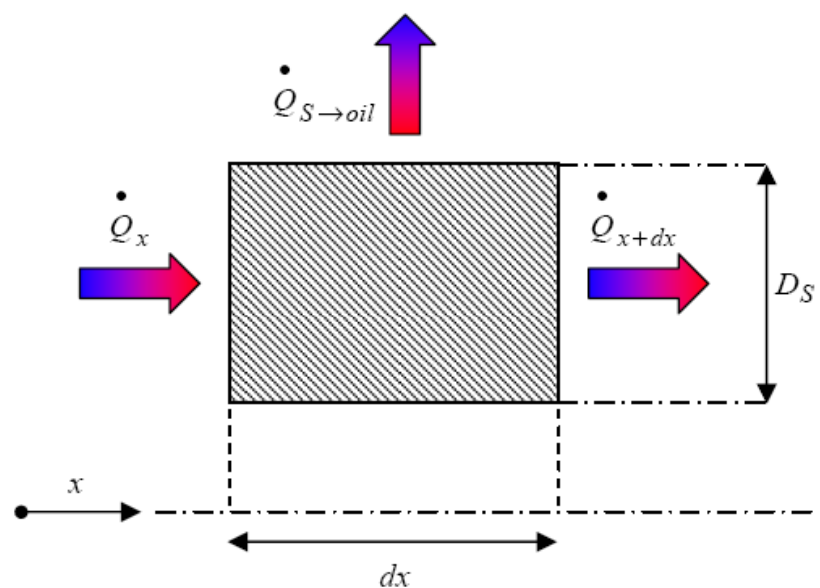

Fig. 27: Heat balance in a single element of the shaft 
TABLES

Table 1: Test conditions

\begin{tabular}{ccccccc}
\hline Speed[rpm]/Load & $16 \mathrm{Nm}$ & $50 \mathrm{Nm}$ & $100 \mathrm{Nm}$ & $150 \mathrm{Nm}$ & $200 \mathrm{Nm}$ & $250 \mathrm{Nm}$ \\
\hline 1000 & $\sqrt{ }$ & $\sqrt{ }$ & $\sqrt{ }$ & & & \\
1500 & $\sqrt{ }$ & $\sqrt{ }$ & $\sqrt{ }$ & $\sqrt{ }$ & $\sqrt{ }$ & $\sqrt{ }$ \\
2000 & $\sqrt{ }$ & $\sqrt{ }$ & $\sqrt{ }$ & $\sqrt{ }$ & $\sqrt{ }$ & $\sqrt{ }$ \\
2500 & $\sqrt{ }$ & $\sqrt{ }$ & $\sqrt{ }$ & $\sqrt{ }$ & $\sqrt{ }$ & \\
3000 & $\sqrt{ }$ & $\sqrt{ }$ & $\sqrt{ }$ & $\sqrt{ }$ & $\sqrt{ }$ & \\
\hline
\end{tabular}

Table 2: Surface temperature of the turbine and compressor casing

\begin{tabular}{|c|c|c|c|c|c|c|c|c|c|}
\hline \multirow[b]{2}{*}{$\begin{array}{c}\text { Temperatures } \\
{[\mathrm{K}] \rightarrow}\end{array}$} & \multicolumn{3}{|c|}{ COMPRESSOR } & \multirow[b]{2}{*}{$\Delta \mathrm{T}_{\mathrm{C}, \text { Eng-Ext }}$} & \multirow[b]{2}{*}{ Engine } & \multicolumn{2}{|c|}{ TURBINE } & \multirow[b]{2}{*}{$\Delta \mathrm{T}_{\mathrm{T}, \mathrm{Eng} \text {-Ext }}$} & \multirow[b]{2}{*}{$\begin{array}{l}\text { Exhaust } \\
\text { gases }\end{array}$} \\
\hline & Engine & Top & External & & & Top & External & & \\
\hline & & & & & & & & \multicolumn{2}{|c|}{ Engine speed: $1000 \mathrm{rpm}$} \\
\hline \multicolumn{10}{|l|}{$8 \mathrm{Nm}$} \\
\hline Inner $[\mathrm{K}]$ & 307 & 306 & 304 & $\approx 3$ & 373 & 364 & 363 & $\approx 10$ & 388 \\
\hline Outer [K] & 315 & 307 & 304 & $\approx 11$ & 371 & 362 & 357 & $\approx 14$ & \\
\hline $\begin{array}{l}\Delta T_{w} \\
50 \mathrm{Nm}\end{array}$ & $\approx-8$ & $\approx-1$ & $\approx 0$ & & $\approx 2$ & $\approx 2$ & $\approx 6$ & & \\
\hline Inner [K] & 313 & 311 & 309 & $\approx 4$ & 459 & 446 & 436 & $\approx 23$ & 506 \\
\hline Outer [K] & 322 & 311 & 309 & $\approx 13$ & 454 & 440 & 409 & $\approx 44$ & \\
\hline \multirow[t]{2}{*}{$\Delta \mathrm{T}_{\mathrm{w}}$} & $\approx-9$ & $\approx 0$ & $\approx 0$ & & $\approx 5$ & $\approx 6$ & $\approx 17$ & & \\
\hline & & & & & & & & \multicolumn{2}{|c|}{ Engine speed: $1500 \mathrm{rpm}$} \\
\hline \multicolumn{10}{|l|}{$8 \mathrm{Nm}$} \\
\hline Inner [K] & 309 & 308 & 306 & $\approx 3$ & 376 & 375 & 370 & $\approx 6$ & 417 \\
\hline Outer [K] & 317 & 308 & 306 & $\approx 11$ & 373 & 372 & 361 & $\approx 12$ & \\
\hline $\begin{array}{l}\Delta T_{\mathrm{w}} \\
250 \mathrm{Nm}\end{array}$ & $\approx-8$ & $\approx 0$ & $\approx 0$ & & $\approx 3$ & $\approx 3$ & $\approx 9$ & & \\
\hline Inner $[\mathrm{K}]$ & 394 & 382 & 353 & $\approx 41$ & 804 & 800 & 778 & $\approx 26$ & 949 \\
\hline Outer [K] & 423 & 386 & 360 & $\approx 63$ & 788 & 772 & 722 & $\approx 66$ & \\
\hline \multirow[t]{2}{*}{$\Delta \mathrm{T}_{\mathrm{w}}$} & $\approx-29$ & $\approx-4$ & $\approx-7$ & & $\approx 26$ & $\approx 28$ & $\approx 56$ & & \\
\hline & & & & & & & & \multicolumn{2}{|c|}{ Engine speed: 2000 rpm } \\
\hline \multicolumn{10}{|l|}{$8 \mathrm{Nm}$} \\
\hline Inner [K] & 318 & 316 & 307 & $\approx 11$ & 401 & 398 & 393 & $\approx 8$ & 430 \\
\hline Outer [K] & 328 & 317 & 308 & $\approx 20$ & 395 & 394 & 381 & $\approx 14$ & \\
\hline $\begin{array}{l}\Delta \mathrm{T}_{\mathrm{w}} \\
250 \mathrm{~N}\end{array}$ & $\approx-10$ & $\approx-1$ & $\approx-1$ & & $\approx 6$ & $\approx 4$ & $\approx 12$ & & \\
\hline Inner $[\mathrm{K}]$ & 403 & 391 & 356 & $\approx 47$ & 825 & 827 & 802 & $\approx 23$ & 958 \\
\hline Outer [K] & 435 & 395 & 367 & $\approx 68$ & 809 & 798 & 745 & $\approx 64$ & \\
\hline \multirow[t]{2}{*}{$\Delta T_{w}$} & $\approx-32$ & $\approx-4$ & $\approx-11$ & & $\approx 16$ & $\approx 29$ & $\approx 57$ & & \\
\hline & & & & & & & & \multicolumn{2}{|c|}{ Engine speed: 2500 rpm } \\
\hline \multicolumn{10}{|l|}{$8 \mathrm{Nm}$} \\
\hline Inner [K] & 326 & 324 & 313 & $\approx 13$ & 429 & 429 & 420 & $\approx 9$ & 462 \\
\hline Outer [K] & 339 & 325 & 316 & $\approx 23$ & 424 & 425 & 405 & $\approx 19$ & \\
\hline $\begin{array}{l}\Delta T_{\mathrm{w}} \\
200 \mathrm{Nm}\end{array}$ & $\approx-13$ & $\approx-1$ & $\approx-3$ & & $\approx 5$ & $\approx 4$ & $\approx 15$ & & \\
\hline Inner [K] & 385 & 372 & 350 & $\approx 35$ & 796 & 792 & 775 & $\approx 21$ & 876 \\
\hline Outer [K] & 412 & 376 & 358 & $\approx 64$ & 772 & 777 & 722 & $\approx 50$ & \\
\hline \multirow[t]{2}{*}{$\Delta T_{w}$} & $\approx-27$ & $\approx-4$ & $\approx-8$ & & $\approx 24$ & $\approx 15$ & $\approx 53$ & & \\
\hline & & & & & & & & \multicolumn{2}{|c|}{ Engine speed: 3000 rpm } \\
\hline \multicolumn{10}{|l|}{$16 \mathrm{Nm}$} \\
\hline Inner [K] & 342 & 338 & 336 & $\approx 6$ & 475 & 474 & 467 & $\approx 8$ & 512 \\
\hline Outer [K] & 358 & 339 & 337 & $\approx 21$ & 468 & 468 & 450 & $\approx 18$ & \\
\hline $\begin{array}{l}\Delta \mathrm{T}_{\mathrm{w}} \\
200 \mathrm{Nm}\end{array}$ & $\approx-16$ & $\approx-1$ & $\approx-1$ & & $\approx 7$ & $\approx 6$ & $\approx$ & & \\
\hline Inner [K] & 391 & 380 & 360 & $\approx 11$ & 805 & 792 & 782 & $\approx 23$ & 933 \\
\hline Outer [K] & 420 & 385 & 363 & $\approx 37$ & 778 & 768 & 725 & $\approx 53$ & \\
\hline$\Delta \mathrm{T}_{\mathrm{w}}$ & $\approx-29$ & $\approx-5$ & $\approx-3$ & & $\approx 27$ & $\approx 24$ & $\approx 57$ & & \\
\hline
\end{tabular}


Table 3: Adiabatic and non-adiabatic compressor efficiency and exit temperature

\begin{tabular}{|c|c|c|c|c|c|c|c|c|c|}
\hline $\begin{array}{c}\text { exh gas } \\
{[\mathrm{K}]}\end{array}$ & PR & $\begin{array}{c}\text { MFP } \\
{\left[1 \times 10^{-5}(\mathrm{Kg} / \mathrm{s}) \cdot \sqrt{ } \mathrm{K} / \mathrm{Pa}\right]}\end{array}$ & $\begin{array}{c}\text { Speed } \\
{\left[1 \times 10^{2} \mathrm{rev} / \mathrm{s} \cdot \sqrt{ } \mathrm{K}\right]}\end{array}$ & $\begin{array}{l}\text { Adiabatic } \\
\mathrm{T}_{\text {exit }}[\mathrm{K}]\end{array}$ & $\begin{array}{c}\text { Non-adiabatic } \\
\mathrm{T}_{\text {exit }}[\mathrm{K}]\end{array}$ & $\begin{array}{l}\mathrm{T} \\
{[\mathrm{K}]}\end{array}$ & Adiabatic $\eta_{c}$ & $\begin{array}{c}\text { Non-adiabatic } \\
\eta_{\mathrm{c}}\end{array}$ & $\begin{array}{l}\Delta \eta \\
{[\%]}\end{array}$ \\
\hline 561 & 1.35 & 0.88 & 0.96 & 326 & 335 & 9 & 0.90 & 0.71 & $20 \%$ \\
\hline 596 & 1.40 & 1.00 & 1.24 & 330 & 343 & 13 & 0.91 & 0.69 & $24 \%$ \\
\hline 672 & 1.40 & 0.68 & 1.16 & 330 & 347 & 17 & 0.9 & 0.65 & $27 \%$ \\
\hline 698 & 1.40 & 0.87 & 1.05 & 330 & 344 & 14 & 0.91 & 0.66 & $26 \%$ \\
\hline 751 & 1.47 & 1.04 & 1.12 & 335 & 353 & 18 & 0.93 & 0.66 & $29 \%$ \\
\hline 755 & 1.57 & 0.87 & 1.13 & 345 & 363 & 18 & 0.91 & 0.68 & $25 \%$ \\
\hline 816 & 1.64 & 1.02 & 1.21 & 350 & 363 & 13 & 0.92 & 0.74 & $19 \%$ \\
\hline 868 & 1.73 & 0.72 & 1.24 & 364 & 383 & 19 & 0.82 & 0.65 & $20 \%$ \\
\hline 834 & 1.82 & 0.97 & 1.3 & 363 & 394 & 31 & 0.92 & 0.64 & $30 \%$ \\
\hline 949 & 1.85 & 0.71 & 1.32 & 374 & 395 & 21 & 0.82 & 0.66 & $19 \%$ \\
\hline 876 & 1.92 & 1.16 & 1.36 & 368 & 383 & 15 & 0.95 & 0.78 & $17 \%$ \\
\hline 928 & 2.04 & 1.04 & 1.48 & 384 & 404 & 20 & 0.90 & 0.73 & $18 \%$ \\
\hline
\end{tabular}

Table 4: Heat conducted through the turbine casing

\begin{tabular}{|c|c|c|c|c|c|c|c|c|c|c|c|c|}
\hline $\begin{array}{l}\text { Exhaust Gas } \\
{[\mathrm{K}]}\end{array}$ & 853 & 959 & 755 & 834 & 928 & 561 & 698 & 816 & 876 & 596 & 751 & 882 \\
\hline $\begin{array}{l}\text { Comp. heat } \\
{\left[1 \times 10^{5} \mathrm{~W} / \mathrm{m}^{2}\right]}\end{array}$ & $\approx 4.0$ & $\approx 5.3$ & $\approx 2.9$ & $\approx 3.5$ & $\approx 4.5$ & $\approx 1.2$ & $\approx 2.3$ & $\approx 3.2$ & $\approx 3.6$ & $\approx 1.3$ & $\approx 1.5$ & $\approx 3.6$ \\
\hline $\begin{array}{l}\text { Exp. heat } \\
{\left[1 \times 10^{5} \mathrm{~W} / \mathrm{m}^{2}\right]}\end{array}$ & $\approx 3.6$ & $\approx 4.5$ & $\approx 3.3$ & $\approx 3.6$ & $\approx 4.4$ & $\approx 1.4$ & $\approx 2.5$ & $\approx 3.3$ & $\approx 3.8$ & $\approx 1.6$ & $\approx 2.6$ & $\approx 3.4$ \\
\hline $\begin{array}{l}\text { Deviation } \\
\Delta Q[\%]\end{array}$ & -10 & -17 & 13 & 1.6 & -2.3 & 14 & 10 & 1.5 & 4.5 & 18 & 2.2 & -4.1 \\
\hline
\end{tabular}

Table 5: Model validation: compressor non-adiabatic efficiency and compressor exit temperature

\begin{tabular}{|c|c|c|c|c|c|c|c|c|c|c|c|c|}
\hline \multicolumn{13}{|c|}{ Compressor operating conditions } \\
\hline PR & 1.72 & 1.85 & 1.57 & 1.82 & 2.04 & 1.35 & 1.40 & 1.64 & 1.92 & 1.40 & 1.47 & 1.72 \\
\hline $\mathrm{N}\left[1 \times 10^{2}(\mathrm{rev} / \mathrm{s}) \cdot \sqrt{\mathrm{K}}\right]$ & 1.24 & 1.32 & 1.13 & 1.30 & 1.48 & 0.96 & 1.05 & 1.21 & 1.36 & 1.05 & 1.12 & 1.24 \\
\hline MFP $\left[1 \times 10^{-5}(\mathrm{Kg} / \mathrm{s}) \cdot \sqrt{ } \mathrm{K} / \mathrm{Pa}\right]$ & 0.72 & 0.71 & 0.87 & 0.97 & 1.04 & 0.88 & 0.87 & 1.02 & 1.16 & 1.00 & 1.04 & 0.73 \\
\hline \multicolumn{13}{|c|}{ Exit temperature } \\
\hline Experimental Exit temp $[\mathrm{K}]$ & 383 & 395 & 363 & 394 & 404 & 335 & 344 & 363 & 383 & 343 & 353 & 373 \\
\hline Model -Exit temp [K] & 383 & 399 & 360 & 390 & 409 & 337 & 346 & 366 & 388 & 342 & 350 & 373 \\
\hline$\Delta \mathrm{T}[\mathrm{K}]$ & 0 & 4 & 3 & 1 & 5 & 2 & 2 & 3 & 5 & 1 & 3 & 0 \\
\hline \multicolumn{13}{|c|}{ Non-adiabatic efficiency } \\
\hline Experimental - $\eta_{c}$ & 0.65 & 0.66 & 0.68 & 0.65 & 0.72 & 0.72 & 0.68 & 0.75 & 0.80 & 0.69 & 0.67 & 0.73 \\
\hline Model- $\eta_{c}$ & 0.65 & 0.64 & 0.71 & 0.68 & 0.69 & 0.69 & 0.65 & 0.72 & 0.75 & 0.70 & 0.70 & 0.73 \\
\hline$\Delta \eta[\%]$ & 0 & 2 & 3 & 3 & 3 & 3 & 3 & 3 & 5 & 1 & 3 & 0 \\
\hline
\end{tabular}

Table 6: Speeds and temperatures used as input parameters for the model

\begin{tabular}{cccccc}
\hline Turbine Speed $[(\mathrm{rev} / \mathrm{s}) \cdot \sqrt{\mathrm{K}}]$ & \multicolumn{5}{c}{ Temperature exhaust gases $[\mathrm{K}]$} \\
\hline $88.0[90000 \mathrm{rpm}]$ & $550 \mathrm{~K}$ & $650 \mathrm{~K}$ & $750 \mathrm{~K}$ & $850 \mathrm{~K}$ & $950 \mathrm{~K}$ \\
$107.6[110000 \mathrm{rpm}]$ & $550 \mathrm{~K}$ & $650 \mathrm{~K}$ & $750 \mathrm{~K}$ & $850 \mathrm{~K}$ & $950 \mathrm{~K}$ \\
$146.8[150000 \mathrm{rpm}]$ & $550 \mathrm{~K}$ & $650 \mathrm{~K}$ & $750 \mathrm{~K}$ & $850 \mathrm{~K}$ & $950 \mathrm{~K}$ \\
$163.3[170000 \mathrm{rpm}]$ & $550 \mathrm{~K}$ & $650 \mathrm{~K}$ & $750 \mathrm{~K}$ & $850 \mathrm{~K}$ & $950 \mathrm{~K}$ \\
\hline
\end{tabular}


Table 7: Univariate > Outcome: $\eta$

\begin{tabular}{|c|c|c|c|c|}
\hline \multicolumn{5}{|c|}{ Backward swept blades $-\mu \neq 0$} \\
\hline Variable & Coefficient & $95 \% \mathrm{Cl}$ & $p$-value & $\mathrm{R}$ value \\
\hline TP & -0.12834 & $\begin{array}{l}-0.15781 \\
-0.09958\end{array}$ & $<0.0001$ & 0.75 \\
\hline $\log P R$ & 0.76078 & $\begin{array}{c}0.70256 \\
0.819\end{array}$ & $<0.0001$ & 0.760 \\
\hline $\mathrm{M}_{\mathrm{bs}}$ & 0.5105 & $\begin{array}{l}0.46696 \\
0.55405\end{array}$ & $<0.0001$ & 0.718 \\
\hline $\mathrm{M}_{\mathrm{bs}}{ }^{2}$ & 0.356 & $\begin{array}{l}0.32432 \\
0.38767\end{array}$ & $<0.0001$ & 0.700 \\
\hline \multicolumn{5}{|c|}{ Radial blades $-\mu=0$} \\
\hline $\mathrm{Mr}_{\mathrm{r}}$ & 0.34557 & $\begin{array}{l}0.3142 \\
0.3763\end{array}$ & $<0.0001$ & 0.692 \\
\hline $\mathrm{M}_{\mathrm{r}}^{2}$ & 0.17716 & $\begin{array}{l}0.16031 \\
0.19401\end{array}$ & $<0.0001$ & 0.672 \\
\hline
\end{tabular}

Table 8: Multivariate $>$ Outcome: $\eta$

\begin{tabular}{|c|c|c|c|c|}
\hline & & \multicolumn{3}{|c|}{ Backward swept blades $-\mu \neq 0$} \\
\hline Variable & Coefficient & $95 \% \mathrm{Cl}$ & p-value & Adj. $R^{2}$ \\
\hline TP & -0.04158 & $\begin{array}{l}-0.05761 \\
-0.02555\end{array}$ & $<0.0001$ & \multirow{4}{*}{0.9185} \\
\hline $\log P R$ & 0.12336 & $\begin{array}{l}0.03067 \\
0.27739\end{array}$ & $<0.0001$ & \\
\hline $\mathrm{M}_{\mathrm{bs}}{ }^{7}$ & 1.15921 & $\begin{array}{l}1.03487 \\
1.28355\end{array}$ & $<0.0001$ & \\
\hline \multirow[t]{2}{*}{$\mathrm{M}_{\mathrm{bs}}$} & -0.43205 & $\begin{array}{l}-0.55297 \\
-0.31112\end{array}$ & $<0.0001$ & \\
\hline & & & \multicolumn{2}{|c|}{ Radial blades $-\mu=0$} \\
\hline TP & -0.04397 & $\begin{array}{c}-0.06004 \\
-0.0279\end{array}$ & $<0.0001$ & \multirow{4}{*}{0.9021} \\
\hline $\log P R$ & 0.19304 & $\begin{array}{l}0.05870 \\
0.32738\end{array}$ & $<0.0001$ & \\
\hline $\mathrm{Mr}_{\mathrm{r}}$ & 0.89422 & $\begin{array}{l}0.80245 \\
0.98599\end{array}$ & $<0.0001$ & \\
\hline $\mathrm{Mr}_{\mathrm{r}}^{2}$ & -0.28415 & $\begin{array}{l}-0.34211 \\
-0.22618\end{array}$ & $<0.0001$ & \\
\hline
\end{tabular}

Table 9: Typical values of the explanatory variables

\begin{tabular}{cccc}
\hline Value & $\mathrm{M}$ & $\log (\mathrm{PR})$ & $\mathrm{TP}$ \\
\hline Minimum & $\approx 0.5$ & $\approx 0.1$ & $\approx 1.03$ \\
Maximum & $\approx 1.2$ & $\approx 0.38$ & $\approx 2.73$ \\
\hline
\end{tabular}

\footnotetext{
${ }^{7} M_{b s}=$ Mach number back-swept, $M_{r}=$ Mach number radial.
} 
Table 10: Contribution of the explanatory variables to the compressor efficiency and comparison with slip factor

\begin{tabular}{|c|c|c|c|c|}
\hline Variable & $\begin{array}{c}\mathrm{N} \approx 88.0 \\
{[(\mathrm{rev} / \mathrm{s}) \cdot \sqrt{ } \mathrm{K}]}\end{array}$ & $\begin{array}{c}\mathrm{N} \approx 107.6 \\
{[(\mathrm{rev} / \mathrm{s}) \cdot \sqrt{ } \mathrm{K}]}\end{array}$ & $\begin{array}{c}\mathrm{N} \approx 146.8 \\
{[(\mathrm{rev} / \mathrm{s}) \cdot \sqrt{\mathrm{K}}]}\end{array}$ & $\begin{array}{c}\mathrm{N} \approx 163.3 \\
{[(\mathrm{rev} / \mathrm{s}) \cdot \sqrt{\mathrm{K}}]}\end{array}$ \\
\hline $\mathrm{Mr}_{\mathrm{r}}$ & $\approx 72 \%$ & $\approx 74 \%$ & $\approx 78 \%$ & $\approx 79 \%$ \\
\hline $\mathrm{M}_{\mathrm{bs}}$ & $\approx 75 \%$ & $\approx 77 \%$ & $\approx 82 \%$ & $\approx 85 \%$ \\
\hline$\Delta \mathrm{M}\left(=\mathrm{M}_{\mathrm{r}}-\mathrm{M}_{\mathrm{bs}}\right)$ & $\Delta \mathrm{M} \approx-3 \%$ & $\Delta \mathrm{M} \approx-3 \%$ & $\Delta \mathrm{M} \approx-4 \%$ & $\Delta \mathrm{M} \approx-6 \%$ \\
\hline $\mathrm{PR}_{\mathrm{r}}$ & $\approx 5 \%$ & $\approx 6 \%$ & $\approx 8 \%$ & $\approx 10 \%$ \\
\hline $\mathrm{PR}_{\mathrm{bs}}$ & $\approx 3 \%$ & $\approx 4 \%$ & $\approx 5 \%$ & $\approx 6 \%$ \\
\hline$\Delta P R=\left(P R_{r}-P R_{b s}\right)$ & $\Delta \mathrm{PR} \approx 2 \%$ & $\Delta P R \approx 2 \%$ & $\Delta \mathrm{PR} \approx 3 \%$ & $\Delta \mathrm{PR} \approx 4 \%$ \\
\hline $\mathrm{TP}_{\mathrm{r}}$ & $\approx 22 \%$ & $\approx 20 \%$ & $\approx 13 \%$ & $\approx 10 \%$ \\
\hline $\mathrm{TP}_{\mathrm{bs}}$ & $\approx 21 \%$ & $\approx 19 \%$ & $\approx 12 \%$ & $\approx 10 \%$ \\
\hline$\Delta T P=\left(T P_{r}-T_{b s}\right)$ & $\Delta \mathrm{TP} \approx 1 \%$ & $\Delta \mathrm{TP} \approx 1 \%$ & $\Delta \mathrm{TP} \approx 1 \%$ & $\Delta \mathrm{TP} \approx 0 \%$ \\
\hline
\end{tabular}

Table 11: $L D$ values for different combination of $B H L$ and $D$

\begin{tabular}{lllll}
\hline Variable & \multicolumn{1}{c}{$+15 \%$} & \multicolumn{1}{c}{$-15 \%$} & $+30 \%$ & $-30 \%$ \\
\hline \multirow{2}{*}{$\mathrm{BHL}\left(\mathrm{D}_{\text {fixed }}\right)$} & $\mathrm{LD}=0.43$ & $\mathrm{LD}=0.31$ & $\mathrm{LD}=0.48$ & $\mathrm{LD}=0.26$ \\
& $\eta_{\mathrm{var}} \approx 1.8 \%$ & $\eta_{\mathrm{var}} \approx 1.3 \%$ & $\eta_{\mathrm{var}} \approx 1.9 \%$ & $\eta_{\mathrm{var}} \approx 1.0 \%$ \\
$\mathrm{D}\left(\mathrm{BHL}_{\mathrm{fixed}}\right)$ & $\mathrm{LD}=0.32$ & $\mathrm{LD}=0.44$ & $\mathrm{LD}=0.28$ & $\mathrm{LD}=0.53$ \\
& $\eta_{\text {var }} \approx 1.32 \%$ & $\eta_{\text {var }} \approx 1.8 \%$ & $\eta_{\text {var }} \approx 1.0 \%$ & $\eta_{\mathrm{var}} \approx 2.4 \%$ \\
\hline
\end{tabular}

